\title{
Transformation of fly ash based nanosilica extract to BEA zeolite and its durability in hot liquid
}

\author{
Alechine E. Ameh ${ }^{\mathrm{a}, *}$, Olanrewaju O. Fatoba ${ }^{\mathrm{a}}$, Nicholas M. Musyoka ${ }^{\mathrm{b}, \mathrm{d}}$, Benoit Louis ${ }^{\mathrm{c}}$, Leslie \\ F. Petrik ${ }^{\text {a }}$ \\ ${ }^{a}$ Environmental and Nano Science Research Group, Department of Chemistry, University of the Western Cape, Private Bag X17, Bellville, 7535, South Africa \\ ${ }^{\mathrm{b}}$ HySA Infrastructure Centre of Competence, Centre for Nanostructures and Advanced Materials (CeNAM), Chemicals Cluster, Council for Scientific and Industrial \\ Research, P. O Box 395, Pretoria, 0001, South Africa \\ ${ }^{\mathrm{c}}$ Institut de Chimie et Procédés pour l'Energie l'Environnement et la Santé (ICPEES), UMR, 7515, CNRS, Université de Strasbourg, 25 rue Becquerel Strasbourg, F- \\ 67087, Strasbourg, France \\ ${ }^{\mathrm{d}}$ Department of Chemical Sciences, University of Johannesburg, Doornfontein Campus, PO Box 17011, Johannesburg, 2028, South Africa
}

\section{A R T I C L E I N F O}

\section{Keywords:}

Coal fly ash

Nanosilica

BEA

Zeolite

Crystallinity

Crystal size

Framework structure

\begin{abstract}
A B S T R A C T
Power generation in South Africa relies heavily on the combustion of coal and during this process, coal fly ash (CFA) is generated as by-product, which raises several environmental issues. The transformation of CFA into a value added zeolite product is a potential beneficial way to manage and reduce the negative environmental impact of the waste. The present study describes suitable formulations of the synthesis of BEA zeolite from South Africa CFA via an indirect hydrothermal process without the addition of an external silica or aluminium source. Herein, the $\mathrm{Si} / \mathrm{Al}$ ratio of the nanosilica extract significantly increased from 11 to 48, 53 or 61 depending on applied conditions, thus elucidating that the major component in the extract is $92 \%$ silica, with a high purity of $94 \%$. A pure phase BEA zeolite was obtained after the hydrothermal crystallisation of the synthesis precursor with $\mathrm{Si} / \mathrm{Al}$ ratio of 53 or 61 at $140{ }^{\circ} \mathrm{C}$ for 24,48 or $72 \mathrm{~h}$. The BEA zeolites are micron-sized crystals with high thermal framework stability, high surface area and contained mainly framework but some extra framework Al acid sites. Under hot liquid phase treatment, the BEA zeolite framework maintained structural integrity with no phase transformation at elevated treatment duration and temperature.
\end{abstract}

\section{Introduction}

The crystalline aluminosilicate structure of zeolites is usually obtained from high grade and costly reagents. However, zeolites can also be obtained using various natural clays $[1,2]$ and waste by-products including siliceous minerals [3], the biomass of plant waste fly ash [4], electronic waste [5] and CFA. The suitability of CFA over other feedstocks is due to its negligible cost, availability and the sufficient content of $\mathrm{Si}$ and $\mathrm{Al}$. Indeed, the application of suitable reaction conditions using CFA allows the production of different zeolites [6]. The conversion of CFA aluminosilicate content into the crystalline zeolite structure is generally performed using alkali hydrothermal conditions in a closed reactor vessel under high temperature, typically between 100 and $200{ }^{\circ} \mathrm{C}$ for a specified period of time. In addition, this type of reaction occurs in the presence of organic and/or inorganic cations as well as a mineralising agent $[4,7]$.
In the zeolitization process, the CFA aluminate and silicate contents dissolve via hydrolysis and produce a supersaturated solution, which via condensation is then transformed through spontaneous heterogeneous nucleation and crystal growth phase, favoured by hydrothermal treatment [8-10]. The synthesis of CFA based zeolite was successful through the direct or indirect crystallisation processes. Both strategies depend on several factors such as the nature of the alkaline solution, $\mathrm{pH}$, reaction time, reaction temperature, pressure, $\mathrm{Si} / \mathrm{Al}$ ratio, solution/solid ratio and type of aging process [11]. Likewise, the presence of seeds and the nature of structure directing agent (SDA) is also of paramount importance. The production of zeolites from CFA via hydrothermal process has been reported mostly for condensed structures low Si/Al zeolites [9,12]: LTA [13,14], FAU (X) [13,15], GIS (P), CAN [16,17], LTL, SOD [11,18] and ANA [19,20] zeolites.

Over the past decades, many studies dealing with the synthesis of low $\mathrm{Si} / \mathrm{Al}$ zeolite from CFA have shown improvement at both academic

\footnotetext{
* Corresponding author. Tel.: +27219593878.

E-mail addresses: eameh@uwc.ac.za, aeameh1@gmail.com (A.E. Ameh).
} 
laboratories and at pilot plant scale. This has then been translated to an industrial scale with the interest of commercialising the process of CFA conversion to zeolite $[6,21]$. Yet there are considerable limitations associated with the direct and indirect crystallisation processes for the production of high silica zeolites. Only a small fraction of $\mathrm{Al}$ and $\mathrm{Si}$ dissolves from the bulk of CFA. Due to incomplete dissolution, the refractory mineral phases remain inert, thereby hindering the transformation of CFA into pure zeolitic phases via the direct hydrothermal process. Consequently, this compromises the quality of the resulting products, thus yielding a mixture of zeolite, mullite and quartz crystalline phases $[4,11]$. Similarly, this method occurs at low conversion, thereby reducing the transformation efficiency of the zeolite and incorporating a significant amount of CFA into the final product $[9,22$, 23].

Recently, Muniz et al. [24] and Missengue et al. [23] experienced challenges using a two-step hydrothermal process for the production of high silica BEA and ZSM-5. These challenges included: i) the process required the addition of a large amount of fumed silica and ii) the phase purity of the crystalline zeolite was compromised with a blend of mullite, quartz, hematite or amorphous materials. Hence, to overcome these limitations the potential for the recovery of pure $\mathrm{Si}$ or Al components from CFA is eminently important for the recycling of CFA for high silica zeolite production. The objectives are: i) enhance the reactivity of the aluminosilicate species during the dissolution stage, ii) allow the proper control of the molar $\mathrm{Si} / \mathrm{Al}$ ratio promoting the synthesis of high silica zeolite without external addition of silica or alumina sources and iii) improve the crystal purity, framework stability, textural properties, structural activity of high silica zeolites. Recently, Petrik et al. [25], Missengue et al. [26] and Ameh et al. [27] proposed a multi-step process assisted by hydrothermal treatment for the production ZSM-5 and BEA zeolites. Herein, this study proposes to design and optimise the synthesis steps of high silica BEA zeolite from Class F CFA. The focus of the present study includes the extraction of silica, an optimisation of synthesis conditions and molar composition without any extra-addition of silica or alumina sources. Finally, the study aims in the evolution of the structural stability of as-synthesised BEA zeolites in hot liquid phase.

\section{Experimental}

\subsection{Extraction of nanosilica}

Specific amounts of CFA and $\mathrm{NaOH}$ pellets (97\%, Kimix) in a mass ratio of 1:1.2 were ground together vigorously for a few minutes. Then, the obtained homogenous mixture (CFA-NaOH powder) was poured into a porcelain crucible and transferred to a muffle furnace set at $550{ }^{\circ} \mathrm{C}$ for $1.5 \mathrm{~h}$. After the alkaline fusion process, the fused material was cooled to room temperature. Thereafter, the sintered granules of fused fly ash (FFA) were ground into a fine powder using a laboratory scale ball mill grinder and dissolved in deionised water (1:5 solid/liquid ratio $\mathrm{w} / \mathrm{v}$ ) and the filtrate was stored until needed for the extraction process.

The resultant filtrate was treated with concentrated sulphuric acid (95-99\%) until a white precipitate was formed. The white precipitate (FFAE) was dried at $70{ }^{\circ} \mathrm{C}$ overnight and was then heated under reflux with $1.3,1.5$ and $1.7 \mathrm{M}$ oxalic acid $\left(99 \%\right.$, Sigma) at $80{ }^{\circ} \mathrm{C}$ for $6 \mathrm{~h}$ in a solid/liquid ratio $10: 1 \mathrm{w} / \mathrm{v}$. The silica extract was recovered by hot filtration and the solid fraction was then dried overnight at $70{ }^{\circ} \mathrm{C}$ in an oven.

\subsection{Synthesis of BEA zeolite from amorphous silica}

BEA zeolite was synthesised according to the patent procedures [27] with few modifications. $1.905 \mathrm{~g}$ of each extracted nanosilica was mixed separately with $0.1 \mathrm{~g} \mathrm{NaOH}$ (97\%, Kimix), $4.236 \mathrm{~g}$ tetraethylammonium hydroxide (40\% TEAOH, Sigma) and $4.661 \mathrm{~g} \mathrm{H}_{2} \mathrm{O}$ to generate the following molar composition in Table 1.

The synthesis gels were aged for $30 \mathrm{~min}$ at room temperature and then transferred into a $40 \mathrm{ml}$ stainless steel Teflon liner autoclave, which was heated hydrothermally at a set temperature of $140{ }^{\circ} \mathrm{C}$ for a period of $72 \mathrm{~h}$ under static conditions. The resultant solid product was recovered by filtration followed by repeated washing using distilled water, and dried overnight at $70{ }^{\circ} \mathrm{C}$. The removal of the template was performed by calcination at $500{ }^{\circ} \mathrm{C}$ for $4 \mathrm{~h}$ in air with a ramping rate of $5{ }^{\circ} \mathrm{C} / \mathrm{min}$. Furthermore, the effect of $\mathrm{Na}$ or $\mathrm{Al}$ contents and the hydrothermal treatment duration were conducted as described in Tables 2 and 5 . Details of the various amounts of $\mathrm{NaOH}, \mathrm{Al}(\mathrm{OH})_{3}$, and TEAOH, duration are also given in Tables 2 and 5 .

The resulting Na-BEA zeolite samples were changed to the $\mathrm{H}$-form, by treating each sample in $1 \mathrm{M}$ ammonium nitrate $\left(\mathrm{NH}_{4} \mathrm{NO}_{3}\right)$ solution (solid-liquid ratio of $1: 50$ ) at $80{ }^{\circ} \mathrm{C}$ for $2 \mathrm{~h}$ under stirring and the procedure was repeated three times. Upon completion, the recovered $\mathrm{NH}_{4}$ BEA zeolite was calcined in air at a rate of $15^{\circ} \mathrm{C}$ heated at $200{ }^{\circ} \mathrm{C}$ for $2 \mathrm{~h}$ then held for $3 \mathrm{~h}$ at $500{ }^{\circ} \mathrm{C}$ using a ramping rate of $10^{\circ} \mathrm{C} / \mathrm{min}$.

\subsection{Stability test of BEA zeolite}

The stability of the CFA based HBEA zeolites was tested in the hot liquid phase as described by Ameh et al. [27]. $0.5 \mathrm{~g}$ of the HBEA zeolite and $100 \mathrm{~mL}$ of deionised water were added into a $200 \mathrm{~mL}$ Teflon container that was then placed inside an autoclave pressure reactor. Thereafter, the mixture inside the pressure reactor was stirred vigorously at $550 \mathrm{rpm}$ for a period of 6,12 and $24 \mathrm{~h}$ at 150 or $200{ }^{\circ} \mathrm{C}$. After a specific reaction cycle, the autoclave was allowed to cool to room temperature and treated HBEA zeolites were filtered and dried at $80{ }^{\circ} \mathrm{C}$ overnight for further characterisation.

\subsection{Characterisation}

The morphology and size of HBEA zeolites were observed by scanning electron microscopy (SEM). The SEM images were obtained using a Zeiss Gemini Aurga equipped with a CDU-lad detector at $25 \mathrm{kV}$. XRD was carried out on a Philips X-pert pro MPD X-ray diffractometer using $\mathrm{Cu}-\mathrm{K}$ radiation at $40 \mathrm{kV}$ and $40 \mathrm{~mA}$ in the range of $5-60^{\circ} 2 \theta$ with a step size of $0.02^{\circ} / \mathrm{s}$. The elemental compositions of the zeolites were determined by inductively coupled plasma optical emission spectrometry (ICP-OES) using a Varian Liberty II spectrometer. X-ray fluorescence spectroscopy (XRF) analysis was done on Philips PW 1480 X-ray fluorescence spectrometer. Thermogravimetric analysis was carried out using Setaram Setsys Evolution 16 TGA-DTA-DSC set at a heating ramp of $5{ }^{\circ} \mathrm{C} / \mathrm{min}$ up to $900^{\circ} \mathrm{C}$ under a flow of $50 \mathrm{~mL} / \mathrm{min}$ of air. Typically, 20 $\mathrm{mg}$ of each sample was tested in a crucible. The nitrogen sorption isotherms and Brunauer-Emmett-Teller (BET) surface areas were obtained using a Micrometrics ASAP $2020 \mathrm{HD}$ analyser at $77 \mathrm{~K}$. Prior to each gas sorption experiment, the HBEA samples were degassed down to $10^{-7}$ bar at $200{ }^{\circ} \mathrm{C}$ for at least $8 \mathrm{~h}$.

${ }^{27} \mathrm{Al}$ single pulse MAS NMR experiments were performed at a magnetic field of $11.4 \mathrm{~T}$ on a spectrometer with the corresponding Larmor frequencies of $130.3\left({ }^{27} \mathrm{Al}\right)$ and $99.3\left({ }^{29} \mathrm{Si}\right) \mathrm{MHz}$. All single pulse spectra were acquired using a single pulse at $90^{\circ}$ with a recovery delay of $0.5 \mathrm{~s}$ $\left({ }^{27} \mathrm{Al}\right)$ or $25 \mathrm{~s}\left({ }^{29} \mathrm{Si}\right)$. The spectra were accumulated from 1200 scans $\left({ }^{27} \mathrm{Al}\right)$ or 300 scans $\left({ }^{29} \mathrm{Si}\right)$ using a $4 \mathrm{~mm} \mathrm{BBO}$ probe at a spinning rate of $14 \mathrm{kHz}\left({ }^{27} \mathrm{Al}\right)$ and $8 \mathrm{kHz}\left({ }^{29} \mathrm{Si}\right)$ for all experiments. The samples were packed into standard zirconia $4 \mathrm{~mm}$ rotors (Bruker). The ${ }^{27} \mathrm{Al} 3 \mathrm{QMAS}$ NMR spectra were acquired using the z-filter 3QMAS pulse sequence using a $4 \mathrm{~mm}$ probe with sample spinning rate at $14 \mathrm{kHz}$. The optimized

Table 1

Molar composition of nanosilica extract for the synthesis of BEA zeolites.

\begin{tabular}{llllll}
\hline Code name & \multicolumn{5}{l}{ Molar composition } \\
\hline Si-1.3M & $1 \mathrm{Si}$ & $0.022 \mathrm{Al}$ & $0.218 \mathrm{Na}$ & $0.396 \mathrm{TEAOH}$ & $8.906 \mathrm{H}_{2} \mathrm{O}$ \\
Si-1.5M & $1 \mathrm{Si}$ & $0.017 \mathrm{Al}$ & $0.241 \mathrm{Na}$ & $0.399 \mathrm{TEAOH}$ & $8.980 \mathrm{H}_{2} \mathrm{O}$ \\
Si-1.7M & $1 \mathrm{Si}$ & $0.020 \mathrm{Al}$ & $0.217 \mathrm{Na}$ & $0.396 \mathrm{TEAOH}$ & $8.900 \mathrm{H}_{2} \mathrm{O}$ \\
\hline
\end{tabular}


Table 2

Gel composition, crystallinity, crystal size and yield of the different syntheses performed at $140{ }^{\circ} \mathrm{C}$ for $72 \mathrm{~h}$.

\begin{tabular}{|c|c|c|c|c|c|c|c|c|c|c|c|}
\hline \multirow[t]{2}{*}{ Code } & \multicolumn{8}{|c|}{ Molar composition } & \multirow[t]{2}{*}{ Crystal $^{\mathrm{b}}, \%$} & \multirow[t]{2}{*}{ Crystal $^{\mathrm{c}}$ size, $\mu \mathrm{m}$} & \multirow[t]{2}{*}{ Yield ${ }^{\mathrm{d}}, \%$} \\
\hline & $\mathrm{Si}$ & $\mathrm{Al}$ & $\mathrm{Na}$ & $\mathrm{H}_{2} \mathrm{O}$ & TEAOH & $\mathrm{Si} / \mathrm{Na}^{\mathrm{a}}$ & & $\mathrm{Si} / \mathrm{Al}^{\mathrm{a}}$ & & & \\
\hline B1 & 1 & 0.017 & 0.241 & 8.980 & 0.399 & 4.149 & 58.824 & & 70.7 & 0.50 & 25.7 \\
\hline B2 & 1 & 0.017 & 0.317 & 8.980 & 0.399 & 3.155 & 58.824 & & 80.8 & 0.62 & 14.6 \\
\hline B3 & 1 & 0.017 & 0.461 & 8.980 & 0.399 & 2.169 & 58.824 & & 57.0 & 0.86 & 9.0 \\
\hline B4 & 1 & 0.017 & 0.506 & 8.980 & 0.399 & 1.976 & 58.824 & & 100 & 1.95 & 9.9 \\
\hline B5 & 1 & 0.017 & 0.552 & 8.980 & 0.399 & 1.812 & 58.824 & & 27.2 & 1.75 & 5.3 \\
\hline B6 & 1 & 0.017 & 0.734 & 8.980 & 0.399 & 1.362 & 58.824 & & na & na & 19.8 \\
\hline B7 & 1 & 0.060 & 0.241 & 8.980 & 0.399 & 4.149 & 16.667 & & 100 & 0.60 & 30.1 \\
\hline B8 & 1 & 0.098 & 0.241 & 8.980 & 0.399 & 4.149 & 10.204 & & 92.4 & 0.57 & 32.7 \\
\hline B9 & 1 & 0.172 & 0.241 & 8.980 & 0.399 & 4.149 & 5.814 & & 45.7 & 1.75 & 48.9 \\
\hline
\end{tabular}

a Calculated from the metal oxide as determined by XRF of the nanosilica and the amount of $\mathrm{NaOH}$ or $\mathrm{Al}$ added.

b Calculated based on the mass of the recovered product divided by the bulk solid in the synthesis mixture (dry mass).

c The relative crystallinity was determined from the sum of two major peaks intensity at $7.7^{\circ}$ and $22.5^{\circ} 2 \theta$ compared with reference standard (fully crystallised sample).

d The crystal size was determined from SEM using ImageJ software.

pulse widths were $\mathrm{p} 1=4.8 \mathrm{us}, \mathrm{p} 2=1.69$ us and $\mathrm{p} 3=20$ us. In the MQ MAS experiments, 60 transients with a $0.5 \mathrm{~s}$ recycle delay and 512 evolution increments were used. Spectral widths for the F2 (acquisition) and $\mathrm{F} 1$ (evolution) dimension were 50 and $14 \mathrm{kHz}$, respectively. All spectra were externally referenced (at $0 \mathrm{ppm}$ ) to a $0.1 \mathrm{M} \mathrm{Al}\left(\mathrm{NO}_{3}\right)_{3}$ and TMS (neat) solution.

\section{Results and discussion}

\subsection{Characterisation of extracted nanosilica from CFA}

The XRD patterns of CFA and oxalic acid refluxed FFAE using different concentrations of oxalic acid of $1.3,1.5$ and $1.7 \mathrm{M}$ are shown in Fig. 1.

The XRD pattern of the CFA as presented in Fig. 1, exhibits glassy amorphous phases between 20 and $40^{\circ} 2 \theta$. Besides, two major phases, mullite and quartz, were observed, while the other mineral phases embedded within the CFA matrix particles are hematite and magnetite. The hump observed at lower diffraction angle between 20 and $34^{\circ} 2 \theta$ confirms that CFA contained amorphous glassy materials. After the extraction process using fusion, precipitation and oxalic treatment, the mineral phases in CFA were completely transformed into amorphous materials that exhibited a broad hump (Fig. 1 Si-1.3 M - Si-1.7 M). The hump between 15 and $37^{\circ} 2 \theta$ typically characterises amorphous silica

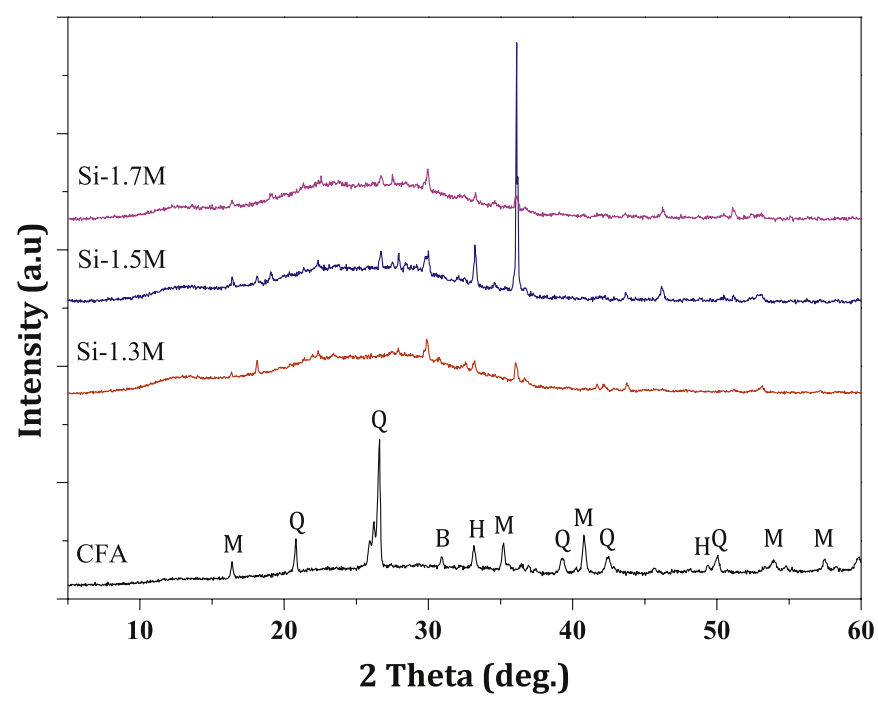

Fig. 1. XRD patterns of CFA and extracted silica obtained using 1.3, 1.5 and 1.7 $\mathrm{M}$ oxalic acid under reflux at $80{ }^{\circ} \mathrm{C}$ for $6 \mathrm{~h}$.
[28]. A significant increase in peak intensity at $36^{\circ} 2 \theta$ of Si-1.5 M was observed compared to Si-1.3 M and Si-1.7 M. This indicates the presence of an induced crystalline nanosilica phase [29]. Moreso, the spherical particles of the respective mineral phases in the CFA (Fig. S1) were totally transformed into spheroidal nanoparticles of amorphous material generally smaller than $200 \mathrm{~nm}$ (Figs. S1b-d). Mor et al. [30] described such morphology obtained from agricultural waste as silica nanoparticles.

FT-IR was also used to investigate which vibrations are present in the different samples (Fig. S2 and Table 3). The vibrations located at 455, 795 and $1065 \mathrm{~cm}^{-1}$ can be assigned to $\mathrm{Si}-\mathrm{O}-\mathrm{Si}$ bonds, corresponding to bending vibration mode, symmetrical stretching and asymmetrical stretching vibrations of the siloxane structure respectively [30,31]. Moreso, the identified functional group of $\mathrm{Si}-\mathrm{O}-\mathrm{T}, \mathrm{Si}-\mathrm{O}$ and $\mathrm{Si}-\mathrm{OH}$ bending and stretching bands in the extracted CFA based nanosilica were similar to the FT-IR bands present in commercial fumed silica as noticed by Li et al. [32] (Table 1).

This clearly validated the fact that the mineral phases of the CFA (Fig. 1) are completely transformed into suitable $\mathrm{SiO}_{2}$ and aluminosilicate species as suggested by XRD and SEM in Figs. 1 and S1, respectively.

Table 4 presents the elemental composition of the extracted nanoparticles from CFA. After the alkaline fusion and precipitation process, the amount of $\mathrm{Na}$ in the FFAE precipitate was greatly enhanced to $53 \%$ (Table 1) due to the thermal fusion of CFA with $\mathrm{NaOH}$. On the other hand, the content of $\mathrm{Al}$ oxide reduced significantly from $27 \mathrm{wt} \% \mathrm{CFA}$ to $3 \mathrm{wt} \%$ in FFAE which in turn influenced the increase in $\mathrm{Si} / \mathrm{Al}$ ratio of CFA from 2 to 11 (FFAE). However, the high amount of Na content alongside other major metal oxide remained superior to $0.1 \mathrm{wt} \%$, which may hinder the formation of high silica zeolite. Upon oxalic acid treatment, about $87 \%$ of the $\mathrm{Na}$ in FFAE was removed which greatly diminished the $\mathrm{Na}$ content $(<8 \mathrm{wt} \%)$ along with other metal oxides $(<0.08 \mathrm{wt} \%)$ in the extracted silica nanoparticles except for $\mathrm{Al}$ oxide which remained above $1 \mathrm{wt} \%$ (Table 1 ). In addition, a recovery of about

Table 3

Comparison of extracted CFA based nanosilica and pure fumed silica.

\begin{tabular}{|c|c|c|c|}
\hline \multirow[t]{2}{*}{ Bands } & \multicolumn{2}{|c|}{ Type of silica band $\left(\mathrm{cm}^{-1}\right)$} & \multirow[t]{2}{*}{ Assignment } \\
\hline & $\begin{array}{l}\text { Fumed silica (Li } \\
\text { et al., 2014) }\end{array}$ & $\begin{array}{l}\text { CFA based silica } \\
\text { (This work) }\end{array}$ & \\
\hline $\mathrm{Si}-\mathrm{O}-\mathrm{T}(\mathrm{T}=\mathrm{Al}$ & 468 & 455 & Bending vibration \\
\hline or $\mathrm{Si}$ ) & 802 & 795 & $\begin{array}{l}\text { Symmetric } \\
\text { stretching }\end{array}$ \\
\hline $\mathrm{Si}-\mathrm{O}$ & 969 & 939 & Asymmetric \\
\hline $\mathrm{Si}-\mathrm{O}-\mathrm{T}$ & 1087 & 1065 & stretching \\
\hline $\mathrm{CO}_{3}$ & - & 1417 & $\begin{array}{l}\text { Carbonate of } \mathrm{Na}, \mathrm{Ca} \\
\text { or } \mathrm{K}\end{array}$ \\
\hline $\mathrm{H}-\mathrm{O}-\mathrm{H}$ & 1628 & 1630 & $\mathrm{H}_{2} \mathrm{O}$ adsorbed \\
\hline
\end{tabular}


Table 4

Elemental composition of the various silica extracts from CFA.

\begin{tabular}{|c|c|c|c|c|c|}
\hline \multirow{2}{*}{$\begin{array}{l}\text { Major } \\
\text { oxides }\end{array}$} & \multirow{2}{*}{$\begin{array}{l}\text { CFA (wt } \\
\%)\end{array}$} & \multirow{2}{*}{$\begin{array}{l}\text { FFAE (wt } \\
\%)\end{array}$} & \multicolumn{3}{|c|}{ FFAE treated with oxalic acid (wt\%) } \\
\hline & & & $\mathrm{Si}-1.3 \mathrm{M}$ & Si-1.5 M & Si-1.7 M \\
\hline $\mathrm{SiO}_{2}$ & $\begin{array}{l}56.52 \pm \\
0.02\end{array}$ & $\begin{array}{l}42.53 \pm \\
0.17\end{array}$ & $\begin{array}{l}91.74 \pm \\
0.930\end{array}$ & $\begin{array}{l}90.98 \pm \\
1.835\end{array}$ & $\begin{array}{l}91.80 \pm \\
0.232\end{array}$ \\
\hline $\mathrm{Al}_{2} \mathrm{O}_{3}$ & $\begin{array}{l}27.45 \pm \\
0.08\end{array}$ & $\begin{array}{l}3.42 \pm \\
0.205\end{array}$ & $\begin{array}{l}1.69 \pm \\
0.078\end{array}$ & $\begin{array}{l}1.31 \pm \\
0.005\end{array}$ & $\begin{array}{l}1.53 \pm \\
0.005\end{array}$ \\
\hline $\mathrm{Fe}_{2} \mathrm{O}_{3}$ & $\begin{array}{l}5.95 \pm \\
0.04\end{array}$ & $\begin{array}{l}0.21 \pm \\
0.027\end{array}$ & $\begin{array}{l}0.07 \pm \\
0.017\end{array}$ & $\begin{array}{l}0.05 \pm \\
0.001\end{array}$ & $\begin{array}{l}0.08 \pm \\
0.017\end{array}$ \\
\hline $\mathrm{CaO}$ & $\begin{array}{l}5.59 \pm \\
0.01\end{array}$ & $\begin{array}{l}0.01 \pm \\
0.002\end{array}$ & - & - & - \\
\hline $\mathrm{TiO}_{2}$ & $\begin{array}{l}1.70 \pm \\
0.01\end{array}$ & $\begin{array}{l}0.01 \pm \\
0.001\end{array}$ & 0.01 & $\begin{array}{l}0.02 \pm \\
0.005\end{array}$ & 0.01 \\
\hline $\mathrm{MgO}$ & $\begin{array}{l}1.70 \pm \\
0.03\end{array}$ & $\begin{array}{l}0.03 \pm \\
0.003\end{array}$ & $\begin{array}{l}0.03 \pm \\
0.012\end{array}$ & $\begin{array}{l}0.05 \pm \\
0.006\end{array}$ & $\begin{array}{l}0.05 \pm \\
0.012\end{array}$ \\
\hline $\mathrm{K}_{2} \mathrm{O}$ & $\begin{array}{l}0.60 \pm \\
0.01\end{array}$ & $\begin{array}{l}0.49 \pm \\
0.043\end{array}$ & $\begin{array}{l}0.07 \pm \\
0.011\end{array}$ & $\begin{array}{l}0.15 \pm \\
0.082\end{array}$ & $\begin{array}{l}0.14 \pm \\
0.07\end{array}$ \\
\hline $\mathrm{P}_{2} \mathrm{O}_{5}$ & $\begin{array}{l}0.39 \pm \\
0.01\end{array}$ & $\begin{array}{l}0.10 \pm \\
0.003\end{array}$ & 0.04 & $\begin{array}{l}0.06 \pm \\
0.012\end{array}$ & 0.04 \\
\hline $\mathrm{MnO}$ & $\begin{array}{l}0.05 \pm \\
0.01\end{array}$ & - & - & - & - \\
\hline $\mathrm{Cr}_{2} \mathrm{O}_{3}$ & $\begin{array}{l}0.03 \pm \\
0.01\end{array}$ & - & - & - & - \\
\hline $\mathrm{V}_{2} \mathrm{O}_{5}$ & 0.02 & - & - & - & - \\
\hline $\mathrm{Na}_{2} \mathrm{O}$ & $\begin{array}{l}0.01 \pm \\
0.01\end{array}$ & $\begin{array}{l}53.20 \pm \\
0.157\end{array}$ & $\begin{array}{l}6.35 \pm \\
0.260\end{array}$ & $\begin{array}{l}7.38 \pm \\
0.918\end{array}$ & $\begin{array}{l}6.35 \pm \\
0.027\end{array}$ \\
\hline Total & 100 & 100 & 100 & 100 & 100 \\
\hline $\mathrm{Si} / \mathrm{Al}$ & 2.06 & 10.98 & 47.88 & 61.14 & 53.04 \\
\hline Purity \% & - & 57.95 & 94.20 & 93.58 & 94.21 \\
\hline Yield \% & - & 50.77 & 44.77 & 44.92 & 44.79 \\
\hline
\end{tabular}

91-92 wt $\% \mathrm{SiO}_{2}$ was observed. Hence, the efficient removal by oxalic acid leaching resulted in silica nanoparticles with almost no impurities.

The percentage purity (\%) and yield (\%) of Si-1.3 M, Si-1.5 M and Si1.7 M was calculated using Eqs. (1) and (2) respectively.

$P(\%)=1-\sum_{i=1} m_{i} \%$

Yield $(\%)=\frac{m_{\text {extract }}}{m_{\text {extract }}+m_{C F A}} \%$

where $m_{i}$, is the mass of the components in the extracted silica expect $\mathrm{SiO}_{2}$, while $m_{\text {extract }}$ and $m_{C F A}$ is the mass of the elemental components in the nanosilica extract and CFA, respectively. The purity of the extracted CFA based samples clearly indicates that the percentage purity increased significantly from $58 \%$ to approximately $94 \%$ when FFAE was treated with oxalic acid (Si-1.3 M, Si-1.5 M and Si-1.7 M), as shown in Table 4. These results further confirm that the main component of the oxalic acid treated FFAE extract is predominately silica. The reduction in product yield suggests that most of the extracted $\mathrm{Al}, \mathrm{Fe}$ and $\mathrm{Ca}$ components and roughly about $14 \%$ Si remain in both the solid residual and solution waste obtained after the separation process. This suggests that the recovered residual and liquid waste could be a suitable recycling material for the synthesis of low silica zeolites. Furthermore, during the treatment of FFAE with oxalic acid, cations such as $\mathrm{Na}, \mathrm{K}, \mathrm{Mg}, \mathrm{Ca}, \mathrm{Fe}$ were chelated into their respectively soluble metal ions as illustrated in Eqs. (3) and (4). This resulted to CFA based nanosilica extract with high $\mathrm{Si} / \mathrm{Al}$ ratio $47 \geq \mathrm{Si} / \mathrm{Al} \leq 61$ which is within the range required for the synthesis of BEA zeolite as suggested by Cao et al. [33].

$$
\begin{aligned}
& \text { Hydrolysis: } \mathrm{Na}_{2} \mathrm{SiO}_{3}+2 \mathrm{CH}_{3} \mathrm{COOH} \rightarrow \equiv \mathrm{Si}-\mathrm{OH}+2 \mathrm{CH}_{3} \mathrm{COONa} \\
& \text { Condensation: } \mathrm{Si}-\mathrm{OH}+\mathrm{HO}-\mathrm{Si} \equiv \rightarrow \equiv \mathrm{Si}-\mathrm{O}-\mathrm{Si} \equiv+\mathrm{H}_{2} \mathrm{O}
\end{aligned}
$$

\subsection{Synthesis of BEA zeolite from CFA based extracted nanosilica}

Fig. 2 shows a comparison of XRD patterns of the zeolite samples synthesised with the nanosilica extracts obtained from the treatment of FFAE with different concentrations of oxalic acid.

The major diffraction peaks at 7.7 and $22.52 \theta$ being assigned to the BEA zeolite phase are observed in all as-synthesised products (Joint Committee on Powder Diffraction Standards (JCPDS); http://www. iza-structure.org/databases/). An in-depth comparison among the diffraction patterns with the Database of Zeolite Structures, undoubtedly confirms that the samples (Si-1.5 M and Si-1.7 M) exhibited a pure BEA zeolite phase (http://www.iza-structure.org/databases/). However, Si1.3 M silica extract contained mainly amorphous phase, which might be due to the high $\mathrm{Al}$ content in the extract. With the increased concentration of oxalic (Si-1.5 M and Si-1.7 M silica extracts), the intensity of the diffraction peaks increased with the appearance of other relevant peaks from the BEA structure and no impurities. This clearly indicates that $\mathrm{CFA}$ based nanosilica extracts with $\mathrm{Si} / \mathrm{Al}$ ratio $\geq 53$ were completely converted to the BEA zeolite mineral phase. These results validate that the purity of the CFA based nanosilica extract allowed its complete solubility and dissolution in the synthesis mixtures. Hence, this promoted the successful formation of pure BEA zeolite phase. The synthesis of BEA zeolite from CFA based nanosilica extracts presents, therefore, an efficient alternative strategy to produce high quality BEA zeolite. The extracted nanosilica, Si-1.5 M was sufficient for achieving pure BEA phase, this condition was set as the optimum for further study described in subsequent subsections.

\subsection{Factors influencing the crystal growth of BEA zeolite from CFA-based nanosilica extract}

\subsubsection{Effect of $\mathrm{NaOH}$}

The XRD patterns of the different BEA zeolites synthesised with different amounts of $\mathrm{Na}$ content in the synthesis mixture are presented in Fig. 3. Details regarding the composition and the names of those samples are also given in Table 2. It is noteworthy that for sample B1, B2, B3 and

Table 5

\begin{tabular}{|c|c|c|c|c|c|c|c|}
\hline Entry & Synthesis time, $\mathrm{h}$ & $\mathrm{Si} / \mathrm{Al}^{\mathrm{a}}$ & $\mathrm{Si} / \mathrm{Al}^{\mathrm{b}}$ & Crystallinity $^{\mathrm{c}} \%$ & Crystal $^{\mathrm{d}}$ size, $\%$ & Yield $^{\mathrm{e}}, \%$ & Phase \\
\hline HB12 & 12 & 58.8 (B1) & na & na & na & na & Amorphous \\
\hline HB24 & 24 & & 28.07 & 61.06 & 0.39 & 21.93 & BEA \\
\hline HB48 & 48 & & 27.51 & 90.09 & 0.41 & 26.71 & BEA \\
\hline HB72 & 72 & & 27.88 & 60.79 & 0.45 & 25.39 & BEA \\
\hline $\mathrm{HB}_{\mathrm{Al}} 12$ & 12 & 16.7 (B7) & na & na & na & na & Amorphous \\
\hline $\mathrm{HB}_{\mathrm{Al}} 24$ & 24 & & na & na & na & na & Amorphous \\
\hline $\mathrm{HB}_{\mathrm{Al}} 48$ & 48 & & 9.31 & 85.21 & 0.78 & 49.09 & BEA \\
\hline $\mathrm{HB}_{\mathrm{Al}} 72$ & 72 & & 11.57 & 100 & 1.07 & 59.30 & BEA \\
\hline
\end{tabular}

Synthesis conditions, crystalline, yield of the solid products and phase formed.

a Calculated from the metal oxide as determined by XRF of the nanosilica and the amount of $\mathrm{NaOH}$ or $\mathrm{Al}$ added.

b Given by ICP analysis of the products.

c The relative crystallinity was determined from the sum of two major peaks intensity at $7.7^{\circ}$ and $22.5^{\circ} 2 \theta$ compared with reference standard (fully crystallised sample).

d The crystal size was determined from SEM using ImageJ software.

e The product yield was determined using equation (2). 


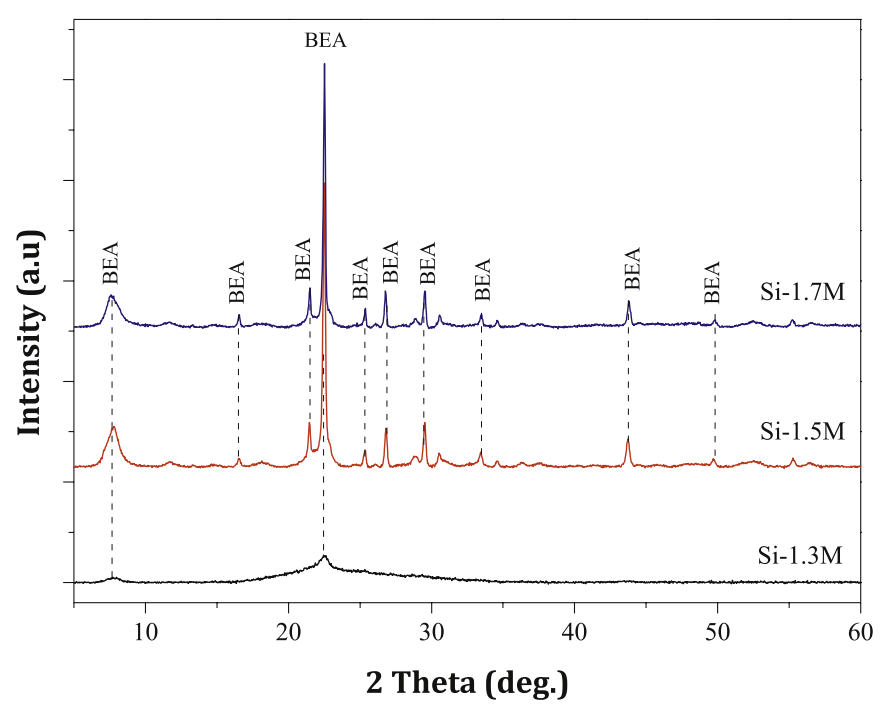

Fig. 2. XRD patterns of the BEA zeolites synthesised from oxalic acid treated nanosilica extracts (at $140{ }^{\circ} \mathrm{C}$ for $72 \mathrm{~h}$ ).

B4 the associated diffraction peaks at 7.7, 13.4, 22.4, 27.1, 28.7, 29.6 and $43.4^{\circ}$ perfectly matched the associated BEA zeolite (Joint Committee on Powder Diffraction Standards, JCPDS). The broad diffraction line at $22.4^{\circ}$, detected in $\mathrm{B} 4$, became narrower as the molar fraction of Na increased (B2, B3 and B4, respectively). According to Yin et al. [34], the narrowing of the main peaks can be associated with increased crystal size. With a further raise in the molar fraction of $\mathrm{Na}$ from 0.506 to 0.552 (B5), other phases were obtained alongside the BEA zeolite, thereby compromising the purity and yield of the synthesised zeolite (Fig. 3 and



Fig. 3. XRD patterns showing the effect of $\mathrm{Na}$ molar fraction on the phase formation of BEA zeolites synthesised hydrothermally at $140{ }^{\circ} \mathrm{C}$ for $72 \mathrm{~h}$.
Table 2). A complete phase transformation was observed when the molar fraction of $\mathrm{Na} \geq 0.734$ (B6). Furthermore, the ternary plot shown in Fig. 4 highlights the effect of altering the molar fraction of $\mathrm{Na}$ in the synthesis mixture ( $\mathrm{Si}$ and $\mathrm{Al}$ are kept constant) on the phase purity and morphology of the synthesised BEA zeolite.

When sample B1 was prepared with $\mathrm{Si} / \mathrm{Na}$ of 4.2 , the crystallinity was $71 \%$, however as the molar ratio was reduced to $3.2 \leq \mathrm{Si} / \mathrm{Na} \leq 2.0$ the prepared B1 and B2 zeolites grew with a crystallinity of 81 and $100 \%$, respectively (Fig. 3 and Table 2). These results corroborate that increasing the amount of $\mathrm{Na}$ content in the synthesis mixture up to a point promoted alkalinity and thus, enhanced the relative crystallinity of the BEA zeolite. Unfortunately, the yield of the product was reduced suggesting that after crystallisation, some redissolved monomers were retained in the supernatant of the reaction mixture.

Under the investigated parameters, with a decrease in the $\mathrm{Si} / \mathrm{Na}$ ratio induced a pronounced effect on the morphology of the crystals. The spheroidal shape ( $\mathrm{Si} / \mathrm{Na}=4.2$ or 3.2 ) gradually changed to a cuboidal crystal habit $(\mathrm{Si} / \mathrm{Na}=2.2$ or 2.0 ) as the synthesis composition became richer in Na (Fig. S3). Similarly, as the B1 and B2 spheroidal morphology changed (crystal size $=0.50$ and $0.62 \mu \mathrm{m}$, respectively), the formed cuboidal habit grew into a large crystal size of 0.86 and $1.95 \mu \mathrm{m}$ (B3 and B4, respectively) (Fig. S3 and Table 2). However, with a further decrease of the $\mathrm{Si} / \mathrm{Na}$ ratio to 1.8 , a mixture of phases was obtained along with BEA zeolites (Fig. 4 and Table 2). Moreso, the crystal size slightly decreased to $1.75 \mu \mathrm{m}$ which can be attributed to the dissolution of the existing BEA zeolite crystal (B5). With the gradual decrease in the $\mathrm{Si} / \mathrm{Na}$ ratio to 1.4 (B6), a complete phase transformation from BEA zeolite to Natrite diffraction peaks was observed (Fig. 3). Furthermore, there is a significant reduction in the product yield as the molar $\mathrm{Si} / \mathrm{Na}$ ratio of the synthesis composition decreased (Table 2).

These results validate that a decrease in $\mathrm{Si} / \mathrm{Na}$ ratio (from 4.2 to 2.0) promoted crystallinity, crystal growth and affected the morphology of CFA based BEA zeolites. Similarly, Zhang et al. [35], noticed that a decrease in $\mathrm{Si} / \mathrm{Na}$ ratio alongside an increase in alkalinity $(\mathrm{pH})$ enhanced the crystallinity and crystal size of BEA zeolite. The low $\mathrm{Si} / \mathrm{Na}$ ratio enabled strong alkalinity of the synthesis composition. This, in turn, improved the nucleation of the BEA zeolite crystals [36]. However, with lower $\mathrm{Si} / \mathrm{Na}$ ratio $(\leq 1.8)$ a competitive environment is created between the cation structure-directing agent of $\mathrm{Na}^{+}$and TEA ${ }^{+}$, in which the high molar fraction of alkali $\mathrm{Na}^{+}$cations directed the formation of

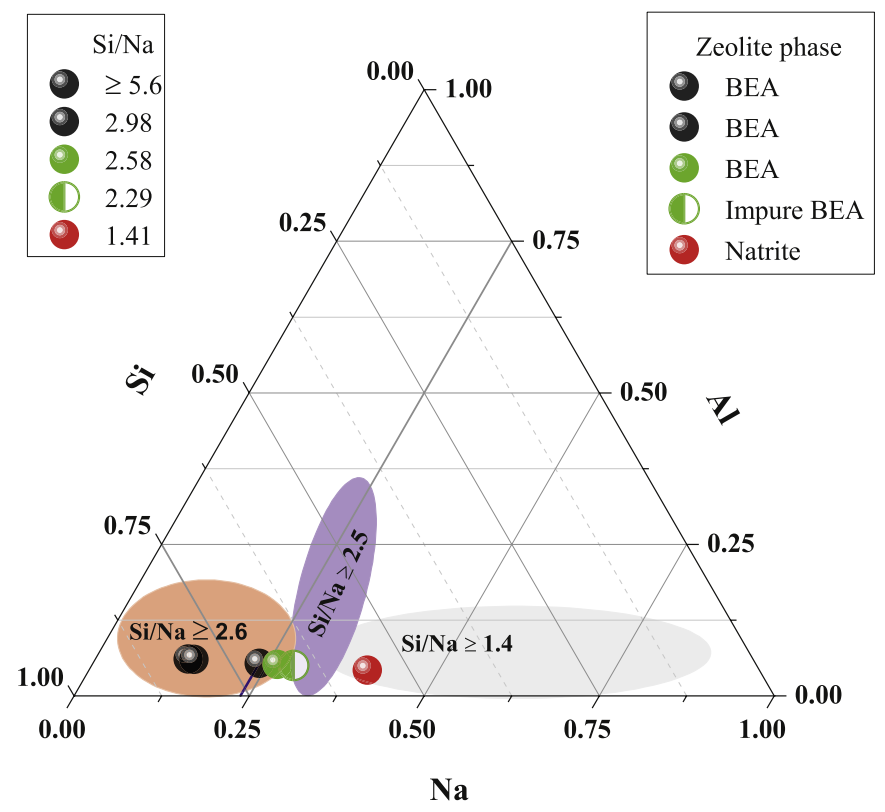

Fig. 4. Ternary diagram representing phase purity as a function of the $\mathrm{Si} / \mathrm{Na}$ ratio in the synthesis mixture. 
another zeolite phase such as Natrite [35,37].

The sodium cations can thus either act as a promoter or hinder the nucleation rate of BEA zeolite depending on the amount of heteroatom within the reactive environment. This is because $\left[\left(\mathrm{AlO}_{2}\right)-\mathrm{Na}^{+}\right]$can be interchanged for $\left[\left(\mathrm{AlO}_{2}\right)^{-} \mathrm{TEA}^{+}\right]$in order to retain smaller $\mathrm{Na}^{+}$cations to create the enabling $\mathrm{T}$-atom environment of the precursor monomers and dimers close enough to that of BEA zeolite [38]. Furthermore, this shows that the competition between $\mathrm{Na}^{+}$and TEA ${ }^{+}$cations to associate as $\left[\left(\mathrm{AlO}_{2}\right)-\mathrm{Na}^{+}\right]$or $\left[\left(\mathrm{AlO}_{2}\right)^{-} \mathrm{TEA}^{+}\right]$clusters in the precursor monomers and dimers have a significant effect on the rate of nucleation of a typical BEA zeolite. Therefore, the obtained results suggest that small molar Na fraction ( $\mathrm{Si} / \mathrm{Na}$ ratio between 2.0 and 4.2 ) provided the best environment for the preparation of highly crystalline BEA zeolite with crystal size between 0.50 and $1.95 \mu \mathrm{m}$ and good product yield.

\subsection{Effect of aluminium}

The XRD patterns presented in Fig. 5 exhibit the characteristic peaks of the BEA zeolites obtained with different molar fractions of aluminium. The diffraction peaks of the baseline sample (B1) with molar fraction of aluminium (0.017) were relatively weak but the peaks at $2 \theta$ $=7.7$ and $22.5^{\circ}$ showed a significant increase in their intensity as the molar fraction of aluminium increased to 0.060 and 0.098 (B7 and B8). This indicates that the crystallinity changed (from $71 \%$ to 100 and $92 \%$ as presented in Table 2) while increasing the aluminium content in the gel.

It was found that the samples with high crystallinity had relatively low recovery yield as presented in Table 3 (B9>B8 $>$ B7). Those yields could however be improved when $\mathrm{NaOH}$ was adjusted previously (B1, B2 and B3). On the other hand, B9 with the highest molar fraction of aluminium (0.172), showed a significant reduction of the diffraction peak intensities $\left(7.7\right.$ and $\left.22.5^{\circ}\right)$ with noticeable disappearance of other BEA zeolite diffractions at 13.4, 27.1, 28.7, 29.6 and $43.4^{\circ}$ (JCPDS). This shows an incomplete conversion of the amorphous feedstock material to BEA zeolite, thereby compromising the crystallinity and crystal phase of the zeolite, below $\mathrm{Si} / \mathrm{Al}$ of 10 (Fig. 5 and Table 2) as already known for BEA zeolite. Thus, the inability to separate the amorphous phase from the crystals promoted the observed yield of B9. Overall, these results suggest that a molar fraction of aluminium between 0.017 and 0.098 is

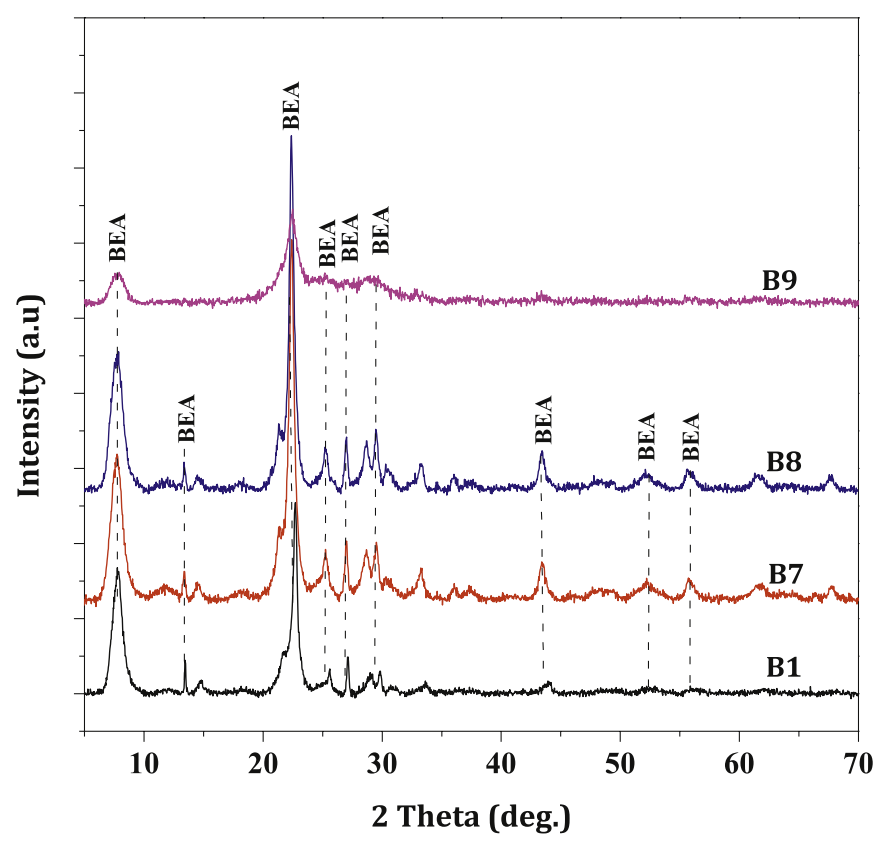

Fig. 5. XRD patterns showing the effect of aluminium on the phase formation of BEA zeolites $140{ }^{\circ} \mathrm{C}$ for $72 \mathrm{~h}$. sufficient to synthesise high purity BEA zeolite with high crystallinity at appreciable yield.

Fig. 6 presents the phase diagram corresponding to the BEA zeolite formation as a function of altering the $\mathrm{Al}$ molar fraction while keeping $\mathrm{Na}$ and Si constant.

The hydrothermal crystallisation of the molar compositions with increasing $\mathrm{Si} / \mathrm{Al}$ ratio from 10.2 to 58.8 confirms that the products were highly crystalline with decreased crystal growth (see Fig. S4 and Table 2). However, as the $\mathrm{Si} / \mathrm{Al}$ ratio of the gel composition was further decreased to 5.8 , the obtained BEA zeolite showed corresponding amorphous material with reduction in crystallinity and increased crystal size (Table 2). It is well known that the high aluminium content in the gel slows the involvement of the silicate species in the formation of crystal nuclei for BEA [39]. The high $\mathrm{Si} / \mathrm{Al}$ ratio in the synthesis mixture allowed easy dissolution of silicon and aluminium species, thereby inducing the mixture to reach super-saturation, which in turn favours nucleation and enables crystal growth [40]. The $\mathrm{Si} / \mathrm{Na}=4.2$ provided sufficient $\mathrm{Na}^{+}$counter ions to act as a charge balancing cations for the $\mathrm{Si} / \mathrm{Al}$ ratio between 16.7 and 58.8 thereby improving the nucleation process which in turn is beneficial for the crystallinity, crystal size and yield of as-prepared BEA zeolite. Interestingly, the decrease of $\mathrm{Si} / \mathrm{Al}$ ratio to 16.7 resulted in an increase of the percentage yield of BEA zeolite between 49 and 59\% depending on the synthesis time.

\subsection{Effect of hydrothermal time}

The effect of hydrothermal synthesis duration was studied on crystallinity, crystal size and yield using the formulations of $\mathrm{B} 1 \mathrm{Si} / \mathrm{Al}=$ $58.8)$ and $\mathrm{B} 7(\mathrm{Si} / \mathrm{Al}=16.7) \mathrm{BEA}$ zeolites. The products characterisation was based on the $\mathrm{H}$-form of the zeolites.

Fig. 7 presents the XRD diffraction patterns of the solids obtained after different hydrothermal treatment duration at $140{ }^{\circ} \mathrm{C}$. After various times applied in the hydrothermal treatment of the two synthesis mixtures (B1-a and B7-b), an amorphous hump between 15 and $30^{\circ} 2 \theta$ was observed in the XRD pattern for the $12 \mathrm{~h}$ case. Prolonging the synthesis time to $24 \mathrm{~h}(\mathrm{Si} / \mathrm{Al}$ ratio $=58.8)$, resulted in significant diffraction peaks at $2 \theta=7.7$ and $22.5^{\circ}$ related to typical HBEA zeolite (HB24), unlike the synthesis mixture with $\mathrm{Si} / \mathrm{Al}$ ratio of 16.7 which retained an amorphous

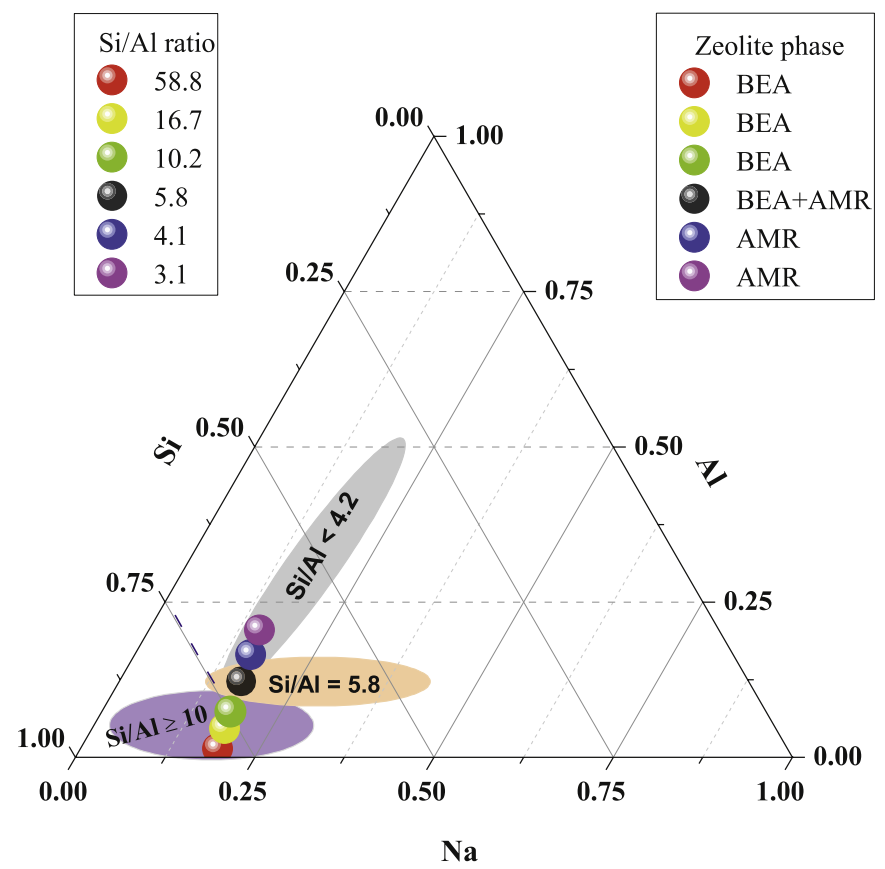

Fig. 6. Ternary diagram representing kinetic phase as a function of molar Na, $\mathrm{Si}$ and $\mathrm{Al}$ fraction in the synthesis mixture. *AMR = amorphous. 
phase $\left(\mathrm{HB}_{\mathrm{Al}} 24\right)$ (Fig. 7). This suggests that $\mathrm{Si} / \mathrm{Al}$ of 16.7 with higher $\mathrm{Al}$ content led to a retarding effect on HBEA phase formation and the crystallisation kinetics. The HBEA product recovered after $72 \mathrm{~h}$ in the case of $\mathrm{HB}_{\mathrm{Al}} 72$ was highly crystalline obtained with the highest yield, thus showing that a higher $\mathrm{Al}$ content favoured crystal growth and phase stability, whereas in the case of molar $\mathrm{Si} / \mathrm{Al}$ ratio of 58.8 the product yield went down indicating phase dissolution (HB72). The results, shown in Fig. 8, correlates the relative crystallinity, $\mathrm{Si} / \mathrm{Al}$ ratio of the synthesis mixture and synthesis time in the different products.

The crystal phase formation can be divided into three stages: i) amorphous (induction period), ii) crystal nuclei formation and iii) stable crystal growth (Fig. 8). At $12 \mathrm{~h}$ synthesis time, the assembled amorphous precursor species had formed but not transformed yet into crystalline material, however, as synthesis time progressed to $24 \mathrm{~h}$ for sample HB24, the precursor species underwent transformation into a completely crystalline material of well-defined crystalline structure except $\mathrm{HB}_{\mathrm{Al}} 24$. Prolonging the synthesis time to 48 and $72 \mathrm{~h}$ allowed crystal growth (highly crystalline material). Principally, as the synthesis time increases, crystallisation and crystal growth were enhanced, indicating that HBEA zeolite can be synthesised from CFA within $24 \mathrm{~h}$ in a low $\mathrm{Al}$ environment. This is an indication that the higher $\mathrm{Si} / \mathrm{Al}$ ratio of 58.8 induced a high nucleation rate and accelerated crystal growth at shorter crystallisation synthesis time compared to the low molar $\mathrm{Si} / \mathrm{Al}$ ratio of 16.7. To this end, an increased aluminium content $(\mathrm{Si} / \mathrm{Al}$ ratio $=$ 16.7) slowed the induction period but eventually promoted crystal growth and yield. Similarly, Manrique et al. [41] and Gabrienko et al. [42] showed that high $\mathrm{Si} / \mathrm{Al}$ ratio in the synthesis mixture reduced the induction process and promoted crystal growth.

It can be seen that a $\mathrm{Si} / \mathrm{Al}$ ratio of 58.8 (synthesis mixture - B1) led to a crystal size of the zeolite products between 0.39 and $0.45 \mu \mathrm{m}$ while a $\mathrm{Si} / \mathrm{Al}$ ratio of 16.7 produced HBEA zeolite crystals of 0.78 and $1.07 \mu \mathrm{m}$ (Table 5, Fig. S5). The crystal size of the synthesised HBEA zeolites gradually increased as hydrothermal time increased. With such steady growth in crystal structure, the dimension of the crystal enlarged as observed. This is due to prolonged hydrothermal time, thereby inducing growth in crystallinity and crystal size of precursor species into micron-

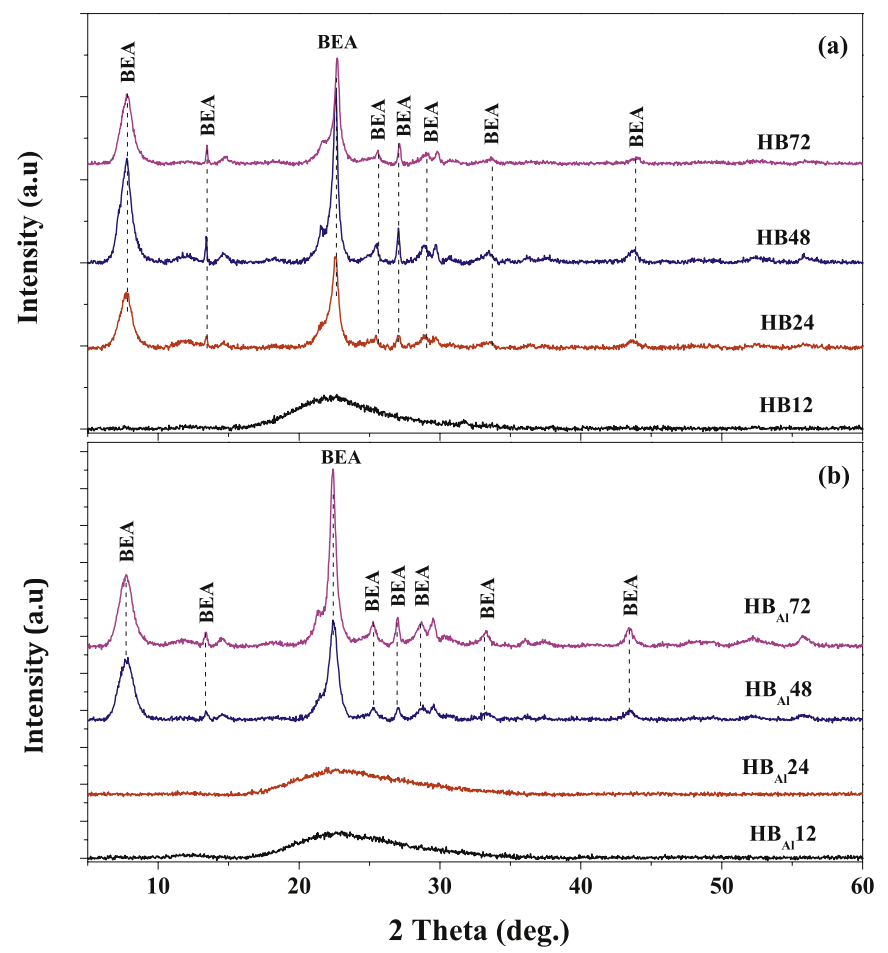

Fig. 7. XRD patterns of the BEA zeolite synthesised at different hydrothermal times using $2 \mathrm{M}$ composition of: a) $\mathrm{Si} / \mathrm{Al}=58.8$ or b) $\mathrm{Si} / \mathrm{Al}=16.7$, respectively.

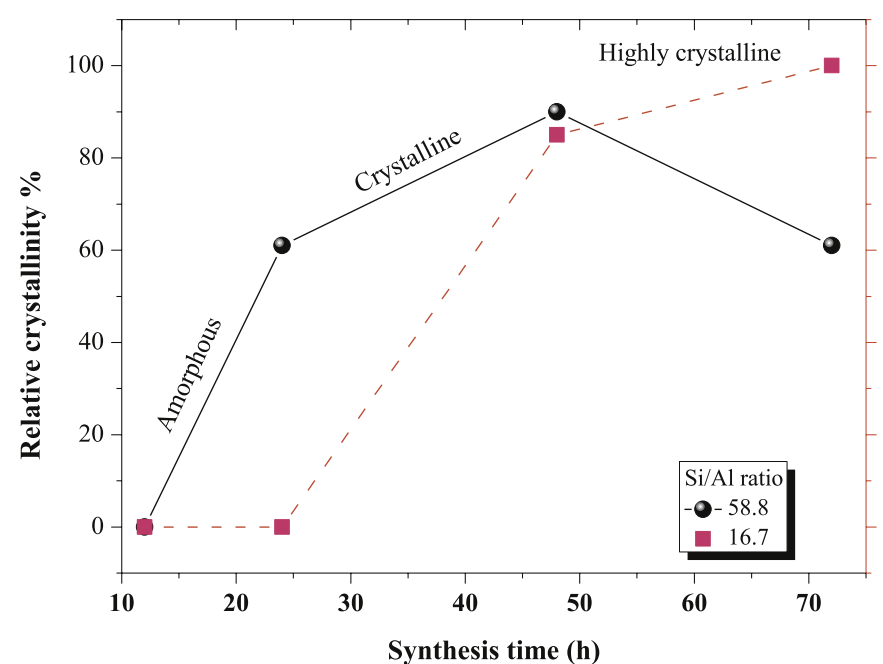

Fig. 8. Graphical presentation of relative crystallinity with respect to synthesis duration for the synthesis of BEA zeolite at $140{ }^{\circ} \mathrm{C}$.

sized crystals $[38,43]$. Hence, in a high $\mathrm{Al}$ environment of 16.7 the aggregation of small precursors at an intermediate stage of synthesis induced the formation of the crystal and provided zeolite structural features with high crystallinity and high yield at prolonged synthesis time. However, in a low $\mathrm{Al}$ environment of $58.8 \mathrm{Si} / \mathrm{Al}$ the extended synthesis time resulted in yield loss.

A considerable difference was noticed in the $\mathrm{Si} / \mathrm{Al}$ ratio of the synthesis formulation compared to the obtained zeolite products (Table 5). The difference between the $\mathrm{Si} / \mathrm{Al}$ ratio of the synthesis mixture and the recovered products could thus be associated with the unreacted Si species, which have remained in solution as can be seen by the $\%$ yield which is lower for formulation B1 than B7. According to Chaves et al. [44] and Mintova et al. [45] the initial Si/Al ratio is different compared to the recovered solid zeolite, especially when $\mathrm{Si} / \mathrm{Al}$ ratio of the synthesis mixture is high.

\subsection{Framework structure and textural properties of the crystalline HBEA zeolite}

Fig. 9 depicts the tetrahedral and octahedral aluminium environments in the different synthesised products using ${ }^{27} \mathrm{Al}$ MAS NMR.

The ${ }^{27} \mathrm{Al}$ MAS NMR spectra of HBEA zeolite samples obtained after different synthesis times using two molar compositions are shown in Fig. 9. Two distinctive Al peaks associated with tetrahedrally coordinated framework aluminium (FAl) or octahedrally coordinated extra framework aluminium (EFAl) located at $\delta=55.3$ or $0.14 \mathrm{ppm}$ (HB24), 58.4 or $2.9 \mathrm{ppm}$ (HB48), 55.3 or $0.04 \mathrm{ppm}$ (HB72), 55.5 or $0.23 \mathrm{ppm}$ $\left(\mathrm{HB}_{\mathrm{Al}} 48\right)$ and 55 or $0.18 \mathrm{ppm}\left(\mathrm{HB}_{\mathrm{Al}} 72\right)$ (Fig. 9) were observed, respectively. Manrique et al. [41] confirmed that the framework aluminium of a typical HBEA zeolite structure is observed between 65 and $40 \mathrm{ppm}$ and the extra framework aluminium between the region of 2.5 and $0 \mathrm{ppm}$.

The extra framework aluminium species of sample HB24 at $\delta=0.14$ ppm experienced an up-field shift to $\delta=2.9 \mathrm{ppm}$ (HB48) and then a downfield shift of $\delta=0.04 \mathrm{ppm}$ (HB72) as the hydrothermal time increased to 48 and $72 \mathrm{~h}$, respectively (Fig. 9). Similarly, as the hydrothermal synthesis time further raised from 48 to $72 \mathrm{~h}, \delta=0.23 \mathrm{ppm}$ $\left(\mathrm{HB}_{\mathrm{Al}} 48\right)$ shifted to lower field $\delta=0.18 \mathrm{ppm}\left(\mathrm{HB}_{\mathrm{Al}} 72\right)$ (Fig. 9). Herein, the chemical shift can be induced by the sensitivity to $\mathrm{Si}-\mathrm{O}-\mathrm{Al}$ bonds and the downfield shift in peak position can be associated with distortions caused by the hydrolysis of $\mathrm{Si}-\mathrm{O}-\mathrm{Si}$ bands [46]. Therefore, the gradually induced distortions can be caused by defects within the framework structure of highly crystalline $\mathrm{HB} 48$ and $\mathrm{HB}_{\mathrm{Al}} 72$ zeolite and this could be associated with dehydroxylation. The percentage of the FAl and EFAl of the HBEA zeolite synthesised at different hydrothermal times was 

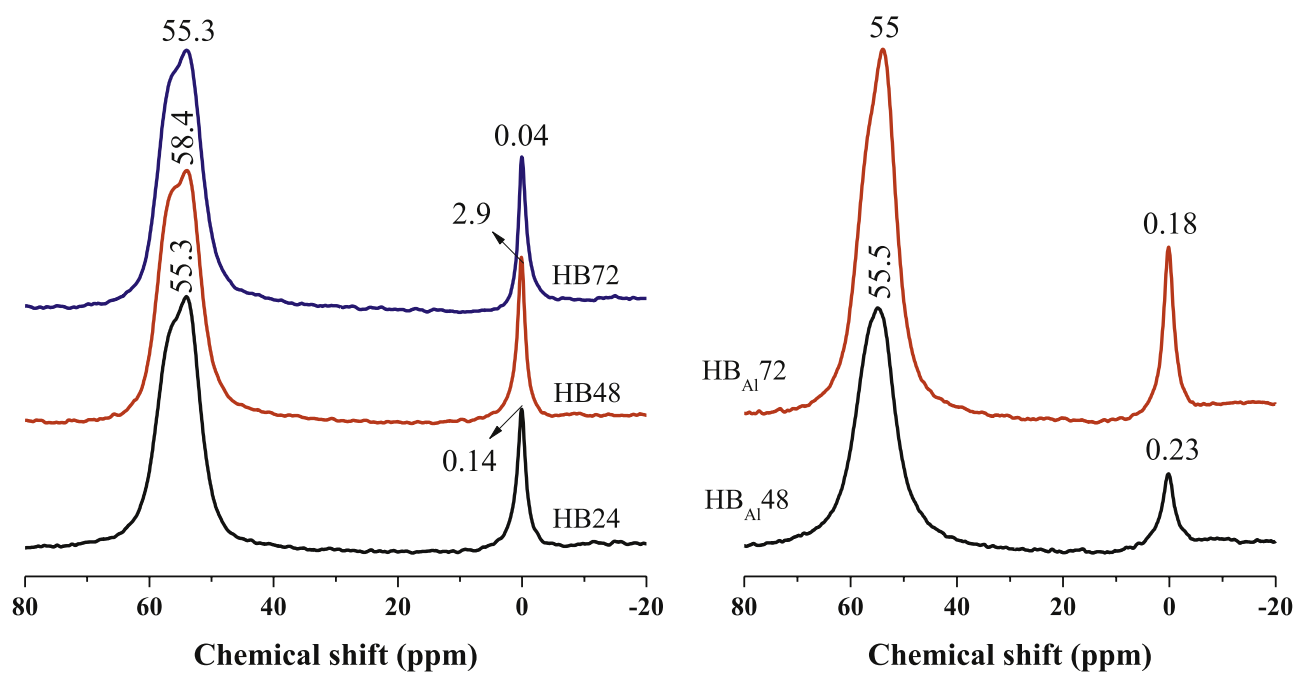

Fig. 9. ${ }^{27} \mathrm{Al}$ MAS NMR of HBEA zeolite synthesised at different hydrothermal time.

calculated from ${ }^{27} \mathrm{Al}$ MAS NMR peaks and is presented in Table 6.

As crystallisation time was increased in the case of $\mathrm{B} 1$, the percentage of framework aluminium (FAl) and extra aluminium framework (EFAl) synthesised at $24 \mathrm{~h}$ was 87.1 and $12.9 \%$, which slightly changed to 86.0 and $14.0 \%$ at $48 \mathrm{~h}$. With prolonged crystallisation time of $72 \mathrm{~h}$, the FAl of HBEA72 increased to 88.2, whilst the EFAl diminished to $11.8 \%$. However, after $24 \mathrm{~h}$ crystallisation time, the synthesis mixture B7 with Si/Al ratio of 16.7 shows only amorphous phase as confirmed by $\mathrm{XRD}$ (Fig. 7, $\mathrm{HB}_{\mathrm{Al}} 24$ ). As the crystallisation time further increased to 48 $\mathrm{h}\left(\mathrm{HB}_{\mathrm{Al}} 48\right)$ the percentage formation of $\mathrm{FAl}$ and EFAl was 87.4 and $12.6 \%$ which FAl diminished after $72 \mathrm{~h}$ to $86.7 \%$, as the EFAl increased to $13.3 \%\left(\mathrm{HB}_{\mathrm{Al}} 72\right)$. Manrique et al. [41] reported that high thermal stability related to the framework $\mathrm{Si} / \mathrm{Al}$ ratio might influence the increase in the framework aluminium (FAl) and decrease the extra framework aluminium (EFAl). The marginal changes of FAl and EFAl was ascribed to the crystallisation time, and the trend observed with deceased $\mathrm{FAl}$ and increased $\mathrm{EFAl}$ can be related to samples with high crystallinity ( $\mathrm{HB} 48$ and $\mathrm{HB}_{\mathrm{Al}} 72$ ). Likewise, the observed trend of increasing extra framework aluminium is directly proportional to increased crystal structure of BEA zeolite (Tables 5 and 6).

According to ${ }^{29}$ Si MAS NMR in Fig. 10, the zeolite samples prepared from the molar composition with $\mathrm{Si} / \mathrm{Al}$ ratio of 58.8 (B1) showed bands at around $\delta=-103$ and $-110 \mathrm{ppm}$ (HB24, HB48 and HB72) while samples $\mathrm{HB}_{\mathrm{Al}} 48$ and $\mathrm{HB}_{\mathrm{Al}} 72$ prepared from $\mathrm{Si} / \mathrm{Al}$ molar ratio of 16.7 have bands around $\delta=-104,-105$ and $-110 \mathrm{ppm}$ (Fig. 10). The bands at $\delta=-103,-104$ and $-105 \mathrm{ppm}$ correspond to $\mathrm{Q}^{3} \mathrm{Si}(1 \mathrm{Al})$, and the bands at $\delta=-114$ are assigned to $\mathrm{Q}^{4} \mathrm{Si}(\mathrm{OAl})$ environment. A weak band at about $\delta=-112$ and $-113 \mathrm{ppm}$, attributed to $\mathrm{Q}^{4} \mathrm{Si}(\mathrm{OAl})$ coordination was observed for all the synthesised HBEA zeolites (Fig. 10). This is in agreement with the bands located in the structural framework of a typical BEA zeolite as reported by Zhang et al. [47]. Further study was conducted by deconvolution of the bands using mixed Lorentzian and Gaussian line shapes in order to calculate the bandwidth, area and

Table 6

Detailed ${ }^{27} \mathrm{Al}$ MAS NMR spectra depicting the integration of $\mathrm{FAl}$ and $\mathrm{EFAl}$ in the HBEA zeolite synthesised at different hydrothermal times.

\begin{tabular}{llll}
\hline Samples & Si/Al ${ }^{\mathrm{a}}$ ratio & FAl \% & EFAl \% \\
\hline HBEA24 & 58.8 & 87.1 & 12.9 \\
HBEA48 & & 86.0 & 14.0 \\
HBEA72 & & 88.2 & 11.8 \\
HBEA $_{\text {Al }} 48$ & 16.7 & 87.4 & 12.6 \\
HBEA $_{\text {Al }}$ & & 86.7 & 13.3 \\
\hline
\end{tabular}

$\mathrm{Si} / \mathrm{Al}^{\mathrm{a}}$ of the synthesis mixture. framework $\mathrm{Si} / \mathrm{Al}$ ratio. The derived framework $\mathrm{Si} / \mathrm{Al}$ ratio was calculated according to Eq. (5) [48].

$\frac{S i}{A l}\left({ }^{29} \mathrm{Si}\right)=\frac{2 . I\left[Q^{2}\{2 A l\}\right]+3 . I\left[Q^{3}\{1 A l\}\right]+4 . I\left[Q^{4}\{0 A l\}\right]}{I\left[Q^{3}\{1 A l\}\right]}$

where I is the peak intensity of $Q^{2}, Q^{3}$ and $Q^{4}$ resonances identified by deconvolution of the ${ }^{29}$ Si MAS NMR spectra. Fig. 10 illustrates $Q^{3}$ and $Q^{4}$ environments of the ${ }^{29} \mathrm{Si}$ MAS NMR spectra.

The chemical shift, bandwidth and area obtained by deconvolution of $\mathrm{Q}^{4} \mathrm{Si}(\mathrm{OAl})$ and $\mathrm{Q}^{3} \mathrm{Si}(1 \mathrm{Al})$ species with the framework $\mathrm{Si} / \mathrm{Al}$ ratio of the synthesised HBEA zeolite samples is presented in Table 7.

Comparing the resultant zeolite products obtained from the two molar compositions with $\mathrm{Si} / \mathrm{Al}$ ratio of either 58.8 (HB24, HB48 and HB72) or $16.7\left(\mathrm{HB}_{\mathrm{Al}} 48\right.$ and $\left.\mathrm{HB}_{\mathrm{Al}} 72\right)$, the $\mathrm{Q}^{3} \mathrm{Si}(1 \mathrm{Al})$ species of samples HBEA24, HBEA48 and HBEA72 was maintained at $\delta=-103$. However, under the same synthesis time of 48 and $72 \mathrm{~h}$, the $\mathrm{Q}^{3} \mathrm{Si}$ (1Al) environment of $\mathrm{HB}_{\mathrm{Al}} 48$ and $\mathrm{HB}_{\mathrm{Al}} 72$ samples experienced a significant chemical shift to $\delta=-105$ and -104 as the $\mathrm{Si} / \mathrm{Al}$ ratio of the molar composition was reduced to 16.7. The upward chemical shift is due to the direct impact of the increased aluminium content within the framework structure of the HBEA zeolites [49]. It is noteworthy, that $\mathrm{HB}_{\mathrm{Al}} 48$ and $\mathrm{HB}_{\mathrm{Al}} 72$ have the lowest computed framework $\mathrm{Si} / \mathrm{Al}_{F W}$ ratio of 14.7 and 20.3, respectively (Table 7), based on Eq. (5).

A trend correlating the bandwidth of $\mathrm{Q}^{3} \mathrm{Si}(1 \mathrm{Al})$ and area of $\mathrm{Q}^{4} \mathrm{Si}$ (0Al) species to the relative crystallinity of the synthesised HBEA zeolites was observed (Tables 6 and 7). When the crystallinity was $61 \%$, the bandwidth and area was $6.3 \mathrm{ppm}$ and 47\% (HB24), respectively. With increased synthesis time to $48 \mathrm{~h}$, the crystallinity raised to $90 \%$ with a shift of the band position of $\mathrm{Q}^{3} \mathrm{Si}(1 \mathrm{Al})$ to $7.2 \mathrm{ppm}$ with a decrease in band area of $\mathrm{Q}^{4} \mathrm{Si}(\mathrm{OAl})$ to $45 \%$ (HB48). However, as the synthesis time reached $72 \mathrm{~h}$, the crystallinity was reduced to $61 \%$ with a shift position of $\mathrm{Q}^{3} \mathrm{Si}(1 \mathrm{Al})$ to $6.6 \mathrm{ppm}$ while the area of $\mathrm{Q}^{4} \mathrm{Si}(0 \mathrm{Al})$ increased to $47 \%$ (HB72). Interestingly, this suggests that as the bandwidth of $\mathrm{Q}^{3} \mathrm{Si}(1 \mathrm{Al})$ was enhanced and the area of $\mathrm{Q}^{4} \mathrm{Si}(0 \mathrm{Al})$ decreased the relative crystallinity of HBEA zeolite increased. Ameh et al. [14] related that the reducing band area of $\mathrm{Q}^{4} \mathrm{Si}(\mathrm{OAl})$ correlated with the relative crystal growth of the zeolite. Hence, the NMR signal of the synthesised CFA based HBEA zeolites related mainly to $\mathrm{Q}^{3} \mathrm{Si}(1 \mathrm{Al})$ and $\mathrm{Q}^{4} \mathrm{Si}(\mathrm{OAl})$ without the formation of terminal $\mathrm{Si}-\mathrm{OH}$ group of structural defects.

\subsection{Textural properties of the synthesised CFA based HBEA zeolites}

The textural properties of the synthesised HBEA zeolites prepared at different hydrothermal times were characterised by $\mathrm{N}_{2}$ adsorption- 

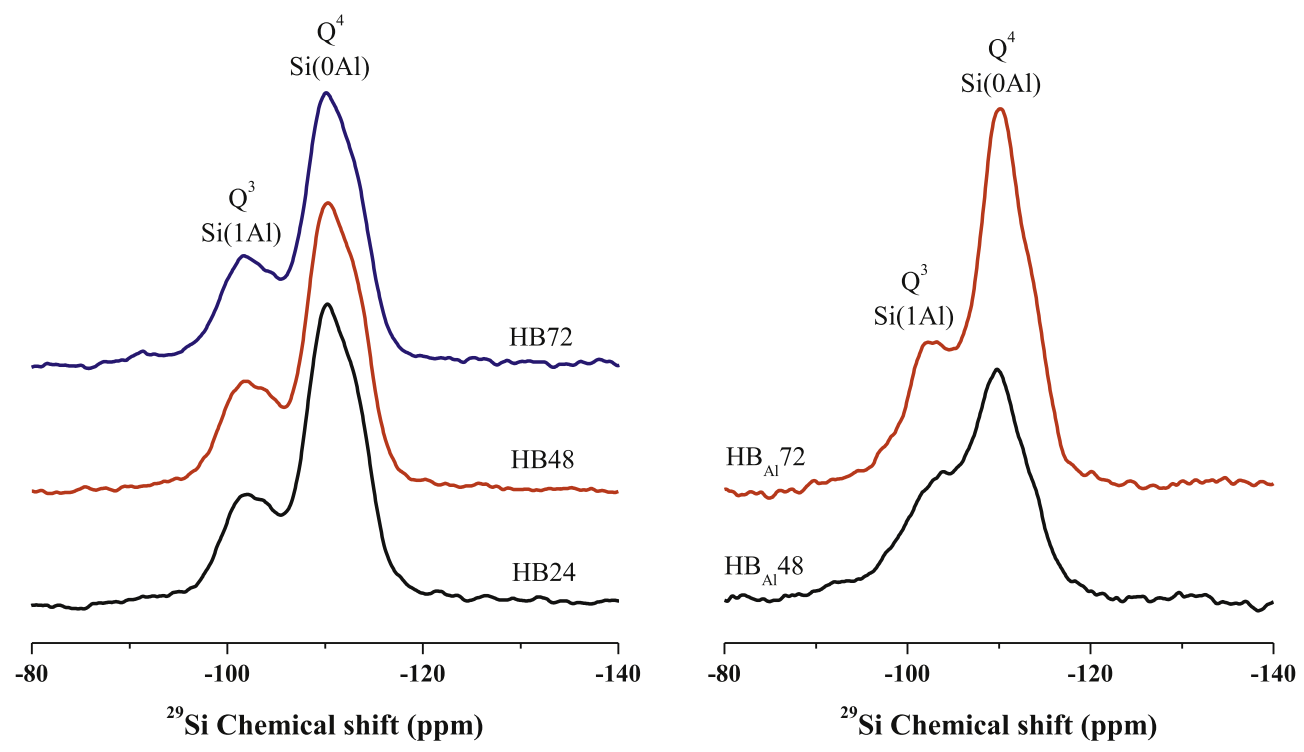

Fig. 10. ${ }^{29}$ Si MAS NMR of HBEA zeolite synthesised at different hydrothermal times.

Table 7

Chemical shift, peak width, peak area and $\mathrm{Si} / \mathrm{Al}_{\mathrm{FW}}$ ratio of deconvoluted $\mathrm{Q}^{3} / \mathrm{Q}^{4}$ environments.

\begin{tabular}{|c|c|c|c|c|c|c|c|}
\hline \multirow[t]{2}{*}{ Samples } & \multirow{2}{*}{$\begin{array}{l}\mathrm{Si} / \\
\mathrm{Al}_{\text {sy }} \\
\text { ratio }\end{array}$} & \multicolumn{2}{|c|}{$\mathrm{Q}^{3} \mathrm{Si}(1 \mathrm{Al})$} & \multicolumn{2}{|c|}{$\mathrm{Q}^{4} \mathrm{Si}(\mathrm{OAl})$} & \multirow{2}{*}{$\begin{array}{l}\mathrm{Si} / \\
\mathrm{Al}_{\mathrm{FW}}\end{array}$} & \multirow{2}{*}{$\begin{array}{l}\mathrm{Si} / \\
\mathrm{Al}_{\mathrm{BEA}}\end{array}$} \\
\hline & & $\begin{array}{l}\delta_{\text {decon }} \\
(\mathrm{ppm})\end{array}$ & $\begin{array}{l}\text { Width } \\
\text { (ppm) }\end{array}$ & $\begin{array}{l}\delta_{\text {decon }} \\
(\mathrm{ppm})\end{array}$ & $\begin{array}{l}\text { Area } \\
\%\end{array}$ & & \\
\hline HBEA24 & 58.8 & -103.3 & 6.3 & -110.7 & 47.0 & 23.5 & 28.1 \\
\hline HBEA48 & & -103.3 & 7.2 & -110.9 & 44.9 & 22 & 27.5 \\
\hline HBEA72 & & -103.1 & 6.6 & -110.8 & 47.1 & 21.8 & 27.9 \\
\hline $\mathrm{HBEA}_{\mathrm{Al}} 48$ & 16.7 & -105.6 & 9.8 & -110.1 & 44.4 & 14.7 & 9.3 \\
\hline $\mathrm{HBEA}_{\mathrm{Al}} 72$ & & -104.5 & 12.4 & -110.5 & 42.4 & 20.4 & 11.6 \\
\hline
\end{tabular}

$\delta_{\text {decon }}$ determined from NMR chemical shifts.

$\mathrm{Si} / \mathrm{Al}_{\mathrm{FW}}$ calculated from the framework structure by NMR.

$\mathrm{Si} / \mathrm{Al}_{\text {BEA }}$ given by ICP analysis.

desorption and the relative isotherms of the samples are presented in Fig. 11. Herein, the nitrogen adsorption/desorption isotherms observed in HB24, HB48 and HB72 samples exhibited both type I and type IV while $\mathrm{HB}_{\mathrm{Al}} 48$ and $\mathrm{HB}_{\mathrm{Al}} 72$ displayed only type I isotherm [50]. The type I isotherms characterise the Langmuir adsorption due to the micropore filling in the region of $P / P_{0}<0.15$ whilst type IV isotherm is due to capillary condensation in the mesopores within the relative pressure of $0.2<P / P_{0}>0.65$. In addition, the hysteresis loop indicates the interconnected mesopores, which do not restrict capillary evaporation of adsorbed nitrogen $[50,51]$. This highlights that HBEA zeolites have both micro- and small mesopores distribution. The textural properties of the various synthesised HBEA zeolites are summarised in Table 8.

The hydrothermal time and $\mathrm{Si} / \mathrm{Al}$ ratio during the formation of the framework structure had an impact on the surface area and mesopore surface area of the product. The BET and mesopore surface area of 722 $\left(\mathrm{m}^{2} / \mathrm{g}\right)$ and $210\left(\mathrm{~m}^{2} / \mathrm{g}\right)$ were obtained after the hydrothermal time of 24 $\mathrm{h}$ (HB24) but after $48 \mathrm{~h}$ treatment time (HB48), the BET and mesopore surface area had reduced to $537\left(\mathrm{~m}^{2} / \mathrm{g}\right)$ and $99\left(\mathrm{~m}^{2} / \mathrm{g}\right)$, respectively. With prolonged hydrothermal reaction (72 h, HB72), the surface area and mesopore area increased to $670\left(\mathrm{~m}^{2} / \mathrm{g}\right)$ and $127\left(\mathrm{~m}^{2} / \mathrm{g}\right)$, respectively (Table 8). Following the observed trends, the decrease in surface area and mesopore area might be associated with high extra-framework aluminium. Samples $\mathrm{HB} 48$ and $\mathrm{HB}_{\mathrm{Al}} 72$ had high crystallinity (90 and $100 \%$, respectively) and slightly higher extra-framework Al but were found to have reduced BET surface area of 538 and $468\left(\mathrm{~m}^{2} / \mathrm{g}\right)$, respectively. According to $\mathrm{Li}$ et al. [52] the crystalline structure can directly influence the mesopore nature and in turn, affect the surface area of BEA zeolites. This suggests that after $24 \mathrm{~h}$ reaction, a faster nucleation formation of agglomerated medium range ordered particles was occurring before crystal growth, but prolonged duration allows better stacking order and structural regularity.

Comparing the textural properties of the samples synthesised at 48 and $72 \mathrm{~h}$, the molar composition with high $\mathrm{Si} / \mathrm{Al}$ ratio of 58.8 resulted in samples having the highest surface area of 722,538 and $670\left(\mathrm{~m}^{2} / \mathrm{g}\right)$, respectively. Whilst, the molar composition with low $\mathrm{Si} / \mathrm{Al}$ ratio of 16.7 showed a reduction in surface area, 307 and $468 \mathrm{~m}^{2} / \mathrm{g}$ of the $\mathrm{HB}_{\mathrm{Al}} 48$ and $\mathrm{HB}_{\mathrm{Al}} 72$, respectively (Table 8). The molar composition with lower $\mathrm{Si} / \mathrm{Al}$ ratio promoted the incorporation of more aluminium into the framework structure of $\mathrm{HB}_{\mathrm{Al}} 48$ and $\mathrm{HB}_{\mathrm{Al}} 72$ which is in agreement with ${ }^{29} \mathrm{Si}$ MAS NMR spectra. Also, the ICP results validate the presence of high aluminium content in $\mathrm{HB}_{\mathrm{Al}} 48$ and $\mathrm{HB}_{\mathrm{Al}} 72$ sample due to their low $\mathrm{Si} / \mathrm{Al}$ ratio of 9.3 and 11.6, respectively (Table 7). Hence, the molar composition with low $\mathrm{Si} / \mathrm{Al}$ ratio impacted upon the increased aluminium content within the framework structure of the synthesised HBEA zeolite, thereby reducing the microporous surface area and mesopore surface area of the zeolite. It is therefore possible to synthesis HBEA zeolite from CFA with a stable framework and high crystalline structure whilst also maintaining high microporosity and mesoporosity, which depended upon the $\mathrm{Si} / \mathrm{Al}$ ratio and the hydrothermal synthesis time.

\subsection{Structural integrity of CFA based HBEA zeolite in hot liquid phase}

Fig. 12 depicts the relationship of total weight loss (TGA) and the area of the $\mathrm{Q}^{4}$ environment (deconvoluted $\mathrm{Q}^{4}$ peak from NMR) to the stability of HBEA zeolite in the liquid phase (Table S1). The structural integrity of the synthesised HBEA zeolite was compared with previous research by Ameh et al. [27] in hot liquid phase. $\mathrm{HB} 72$ and $\mathrm{HB}_{\mathrm{Al}} 72$ were exposed to hot liquid $\left(\mathrm{H}_{2} \mathrm{O}\right)$ at 150 and $200{ }^{\circ} \mathrm{C}$ for 6,12 or $24 \mathrm{~h}$, respectively. The thermal stability and area enlargement of the framework structure of the parent $\mathrm{HB} 72$ and $\mathrm{HB}_{\mathrm{Al}} 72$ zeolite and exposed zeolites are presented in Fig. 12 (Tables S1-S2).

The parent $\mathrm{HB} 72$ and $\mathrm{HB}_{\mathrm{Al}} 72$ zeolite exhibited a total thermal weight loss of 10.78 and $14.60 \%$ which can be associated with water molecules within the porous structure, which \% loss were associated with a $\mathrm{Q}^{4} \mathrm{Si}$ (OAl) area of 11.29 and $12.18 \%$, respectively. Upon treatment of the parent zeolites, it was observed that the $\mathrm{Q}^{4} \mathrm{Si}(0 \mathrm{Al})$ area gradually enlarged to an expansion limit of 16.46 and $15.36 \%$ (Fig. 12a and b) after exposure to hot liquid for $12 \mathrm{~h}$ at $200{ }^{\circ} \mathrm{C}$. These changes can be attributed to the sharp increase in thermal weight loss noticed between 


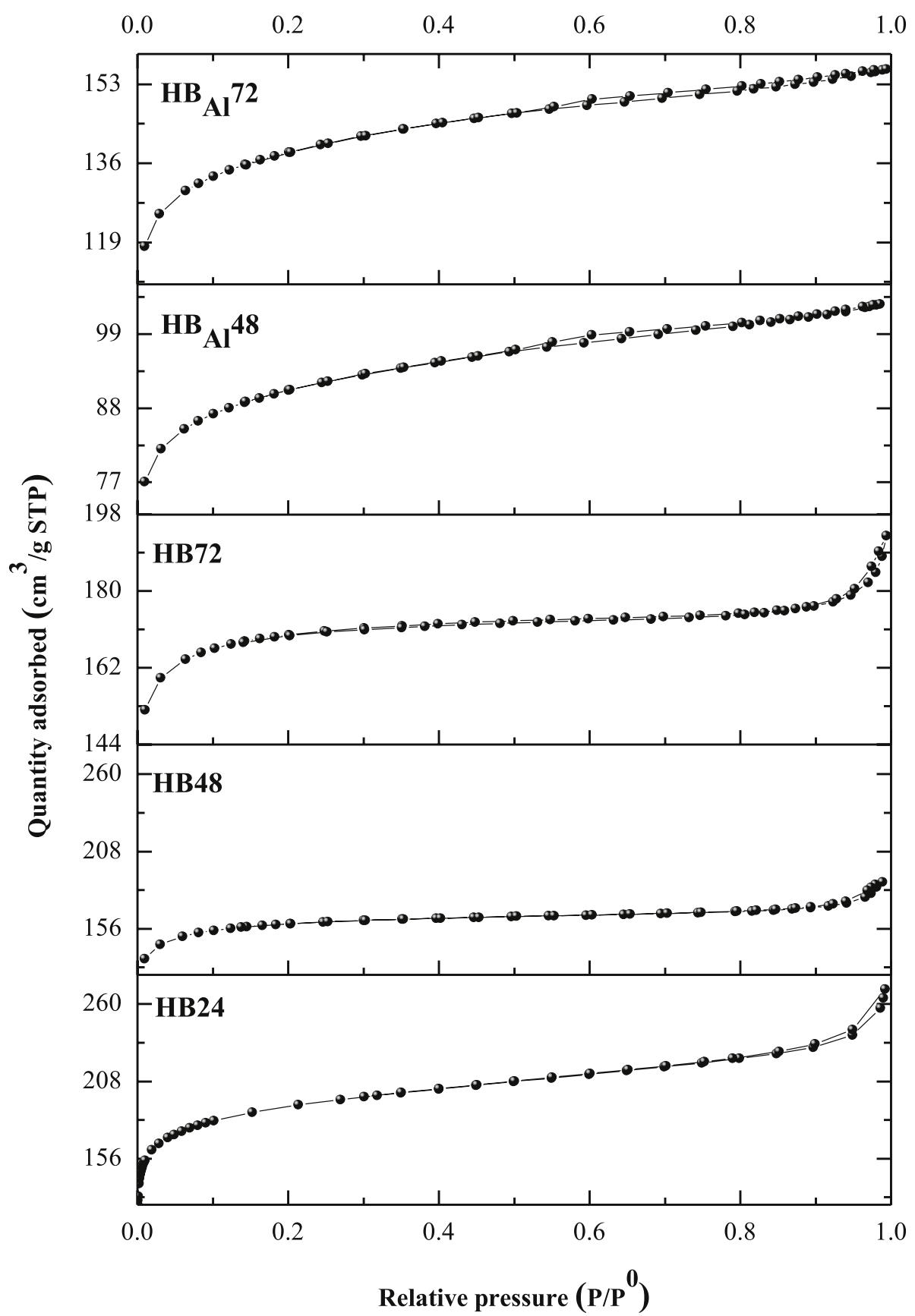

Fig. 11. $\mathrm{N}_{2}$ adsorption-desorption isotherms of BEA zeolite prepared from synthesis composition with different $\mathrm{Si} / \mathrm{Al}$ ratio of 58.8 (HBEA24, HBEA48 and HBEA72) or $16.7\left(\mathrm{HBEA}_{\mathrm{Al}} 48\right.$ and $\left.\mathrm{HBEA}_{\mathrm{Al}} 72\right)$ at $140{ }^{\circ} \mathrm{C}$ for 24,48 and $72 \mathrm{~h}$, respectively.

Table 8

Textural properties of as-synthesised BEA zeolites at different time and Si/Al ratio of the synthesis mixtures.

\begin{tabular}{lllll}
\hline Zeolite & Si/Al ratio & SBET $\left[\mathrm{m}^{2} / \mathrm{g}\right]$ & $\mathrm{S}_{\text {micro }}\left[\mathrm{m}^{2} / \mathrm{g}\right]$ & $\mathrm{S}_{\text {meso }}\left[\mathrm{m}^{2} / \mathrm{g}\right]$ \\
\hline HBEA24 & 58.8 & 722 & 512 & 210 \\
HBEA48 & & 538 & 439 & 99 \\
HBEA72 & & 670 & 543 & 127 \\
HBEA $_{\text {Al }} 48$ & \multirow{2}{*}{16.7} & 307 & 230 & 77 \\
HBEA $_{\text {A1 }}$ & & 468 & 361 & 107 \\
\hline
\end{tabular}

$\mathrm{Si} / \mathrm{Al}$ of the synthesis mixture; $\mathrm{S}_{\mathrm{BET}}$ : $\mathrm{BET}$ surface area; $\mathrm{S}_{\text {micro }}$ : micropore surface area; $S_{\text {micro: }}$ mesopore surface area. the treatment time of 6 and $24 \mathrm{~h}$ at $150{ }^{\circ} \mathrm{C}$ which then reduced to 10.37 and $14.29 \%$, below that of the parent $\mathrm{HB} 72$ and $\mathrm{HB}_{\mathrm{Al}} 72$ zeolite at a treatment time of $6 \mathrm{~h}$ at $200^{\circ} \mathrm{C}$, respectively. At this stage, the difference of 0.4 and $0.3 \%$ in the total weight loss after treatment $\left(6 \mathrm{~h}\right.$ at $\left.200{ }^{\circ} \mathrm{C}\right)$ of the parent zeolite suggests that the porous structure of the zeolite was under attack. With further increase in treatment to 12 and $24 \mathrm{~h}$, the difference in the weight loss increased from 2 to $2.7 \%$ (HB72) and $2.6-3.8 \%\left(\mathrm{HB}_{\mathrm{Al}} 72\right)$ which was associated with the $\mathrm{Q}^{4} \mathrm{Si}(\mathrm{OAl})$ area enlargement reaching the highest limit (Fig. $12 \mathrm{a}$ and $\mathrm{b}$ and Tables S1-S2). Thus, hot liquid exposure at $200{ }^{\circ} \mathrm{C}$ for $24 \mathrm{~h}$ challenged the structural stability of the zeolite, thereby exposing the framework to attack in the liquid phase beyond the life limit of $200^{\circ} \mathrm{C}$ for $24 \mathrm{~h}$. Hence, the treated HBEA zeolites can perform effectively in the liquid phase below this temperature and time. 

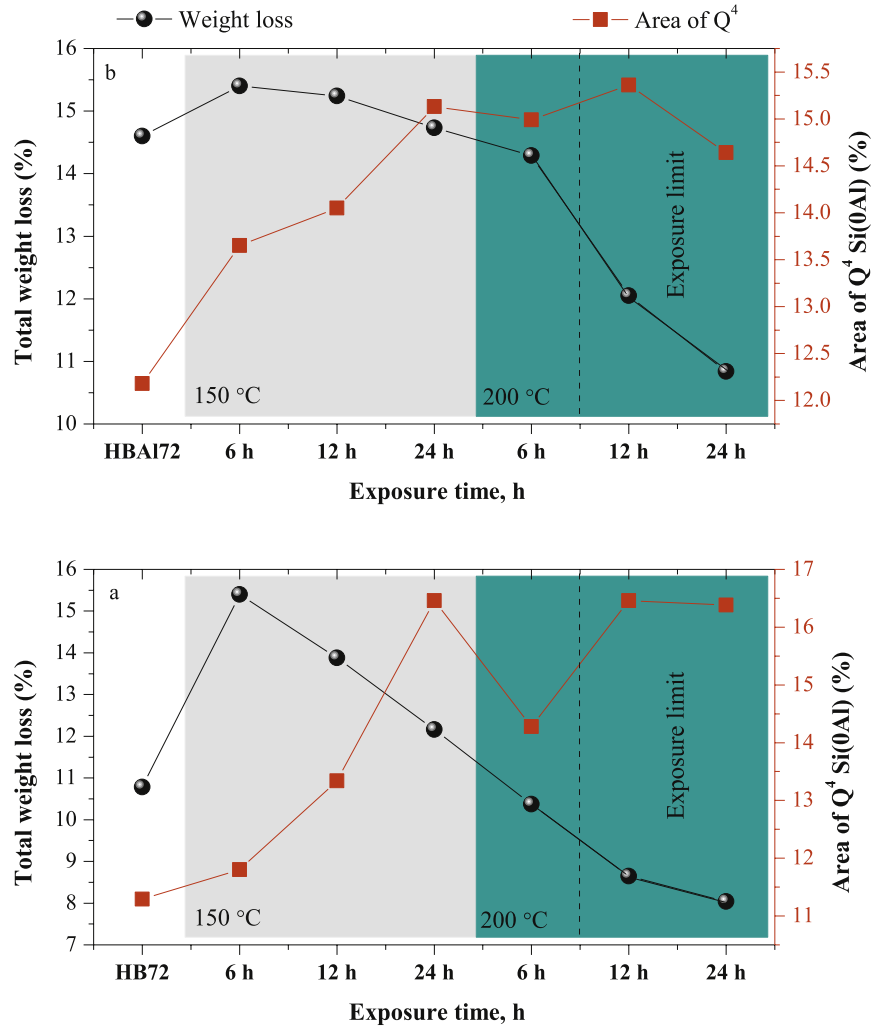

Fig. 12. Structural integrity of parent a) HBEA72 and b) $\mathrm{HBEA}_{\mathrm{Al}} 72$ zeolite treated in hot liquid phase at different exposure times $(6,12$ or $24 \mathrm{~h})$ and temperatures $\left(150\right.$ or $\left.200{ }^{\circ} \mathrm{C}\right)$.

\section{Conclusion}

The multi-step process of the alkaline fusion of the CFA, followed by precipitation of amorphous aluminosilicate, and then oxalic extraction of the precipitate enhanced the purity of the CFA-based nanosilica. Extracted CFA-based silica contains $\mathrm{Si}, \mathrm{Al}$ and $\mathrm{Na}$ with high $\mathrm{Si} / \mathrm{Al}$ ratio which served as a source of the silica needed to synthesis high silica BEA zeolite. Both $\mathrm{Si} / \mathrm{Na}, \mathrm{Si} / \mathrm{Al}$ molar ratio and synthesis time had a significant effect on crystallinity, crystal size and percentage yield of asprepared BEA zeolites. Two distinctive morphologies were associated with the synthesised BEA zeolite i) spheroidal-shaped structure with a crystal size of 0.50 and $0.63 \mu \mathrm{m}$, and ii) large cuboidal-shaped crystal structure of $>0.9 \mu \mathrm{m}$. This could be attributed to the crystal growth that occurred with an increased molar fraction of Na. Hence, the study demonstrated that high molar $\mathrm{Si} / \mathrm{Al}$ ratio in the formulation enhanced both nucleation rate and crystal growth; in addition it also promoted inclusion of framework aluminium within a short synthesis time of $24 \mathrm{~h}$ at $140{ }^{\circ} \mathrm{C}$. This study gave clearly designed synthesis protocols and formulated suitable molar compositions for the production of BEA zeolite from CFA silica extracts. Through this process, the obtained HBEA zeolite products from CFA demonstrated high crystalline structure, suitable thermal stability, stable framework structure with high mesoporosity and excellent surface area and weak/strong acid sites. These characteristic properties validated that those HBEA zeolite will be suitable for different catalytic applications under the liquid phase reaction condition of a life limit not beyond $200{ }^{\circ} \mathrm{C}$ for $24 \mathrm{~h}$.

\section{Declaration of competing interest}

The authors declare that they have no known competing financial interests or personal relationships that could have appeared to influence the work reported in this paper.

\section{CRediT authorship contribution statement}

Alechine E. Ameh: Conceptualization, Methodology, Validation, Investigation, Resources, Writing - original draft, Writing - review \& editing, Visualization. Olanrewaju O. Fatoba: Validation, Writing review \& editing, Visualization. Nicholas M. Musyoka: Validation, Writing - original draft, Writing - review \& editing, Visualization, Supervision. Benoit Louis: Writing - review \& editing, Visualization. Leslie F. Petrik: Validation, Writing - review \& editing, Visualization, Supervision, Funding acquisition.

\section{Acknowledgements}

The authors acknowledge the National Research Foundation and the University of the Western Cape, South Africa for providing the funds needed for this research.

\section{Appendix A. Supplementary data}

Supplementary data to this article can be found online at https://doi. org/10.1016/j.micromeso.2020.110332.

\section{References}

[1] Y. Ma, C. Yan, A. Alshameri, X. Qiu, C. Zhou, D. li, Synthesis and characterization of 13X zeolite from low-grade natural kaolin, Adv. Powder Technol. 25 (2014) 495-499, https://doi.org/10.1016/J.APT.2013.08.002.

[2] A.Á.B. Maia, R.F. Neves, R.S. Angélica, H. Pöllmann, Synthesis, optimisation and characterisation of the zeolite NaA using kaolin waste from the Amazon Region. Production of Zeolites KA, MgA and CaA, Appl. Clay Sci. 108 (2015) 55-60, https://doi.org/10.1016/J.CLAY.2015.02.017.

[3] H. Liu, T. Shen, W. Wang, T. Li, Y. Yue, X. Bao, From natural aluminosilicate minerals to zeolites: synthesis of ZSM-5 from rectorites activated via different methods, Appl. Clay Sci. 115 (2015) 201-211, https://doi.org/10.1016/J. CLAY.2015.07.040.

[4] C. Belviso, State-of-the-art applications of fly ash from coal and biomass: a focus on zeolite synthesis processes and issues, Prog. Energy Combust. Sci. 65 (2018) 109-135, https://doi.org/10.1016/J.PECS.2017.10.004.

[5] V.P. Mallapur, J.U.K. Oubagaranadin, A brief review on the synthesis of zeolites from hazardous wastes, Trans. Indian Ceram. Soc. 76 (2017) 1-13.

[6] M. Wdowin, M. Franus, R. Panek, L. Badura, W. Franus, The conversion technology of fly ash into zeolites, Clean Technol. Environ. Policy 16 (2014) 1217-1223.

[7] M. Moliner, Basic principles of zeolite synthesis, Zeolites Ordered Porous Solids (2011) 37.

[8] X. Querol, J. Umaña, F. Plana, A. Alastuey, A. Lopez-Soler, A. Medinaceli, A. Valero, M. Domingo, E. Garcia-Rojo, Synthesis of zeolites from fly ash at pilot plant scale. Examples of potential applications, Fuel 80 (2001) 857-865, https:// doi.org/10.1016/S0016-2361(00)00156-3.

[9] X. Querol, N. Moreno, J. Umaña, A. Alastuey, E. Hernández, A. López-Soler, F. Plana, Synthesis of zeolites from coal fly ash: an overview, Int. J. Coal Geol. 50 (2002) 413-423, https://doi.org/10.1016/S0166-5162(02)00124-6.

[10] S.S. Bukhari, J. Behin, H. Kazemian, S. Rohani, Conversion of coal fly ash to zeolite utilizing microwave and ultrasound energies: a review, Fuel 140 (2015) 250-266, https://doi.org/10.1016/J.FUEL.2014.09.077.

[11] C. Belviso, F. Cavalcante, S. Fiore, Synthesis of zeolite from Italian coal fly ash: differences in crystallization temperature using seawater instead of distilled water, Waste Manag. 30 (2010) 839-847, https://doi.org/10.1016/J. WASMAN.2009.11.015.

[12] A.D. Elliot, D. Zhang, Controlled release zeolite fertilisers: a value added product produced from fly ash. International Ash Utilization Symposium (IAUS) and World of Coal Ash, WOCA), 2005, pp. 1-32.

[13] N.M. Musyoka, L. Petrik, E. Hums, Synthesis of zeolite A, X and P from a South African coal fly ash. Advanced Materials Research, 2012, pp. 1757-1762.

[14] A.E. Ameh, O.O. Fatoba, N.M. Musyoka, L.F. Petrik, Influence of aluminium source on the crystal structure and framework coordination of $\mathrm{Al}$ and $\mathrm{Si}$ in fly ash-based zeolite NaA, Powder Technol. 306 (2017) 17-25, https://doi.org/10.1016/J. POWTEC.2016.11.003.

[15] N. Shigemoto, H. Hayashi, K. Miyaura, Selective formation of Na-X zeolite from coal fly ash by fusion with sodium hydroxide prior to hydrothermal reaction, J. Mater. Sci. 28 (1993) 4781-4786.

[16] N.M. Musyoka, L.F. Petrik, W.M. Gitari, G. Balfour, E. Hums, Optimization of hydrothermal synthesis of pure phase zeolite Na-P1 from South African coal fly ashes, J. Environ. Sci. Health, Part A. 47 (2012) 337-350.

[17] D. Mainganye, T.V. Ojumu, L. Petrik, Synthesis of zeolites Na-P1 from South African coal fly ash: effect of impeller design and agitation, Materials 6 (2013) 2074-2089.

[18] N.M. Musyoka, L.F. Petrik, G. Balfour, W.M. Gitari, E. Hums, Synthesis of hydroxy sodalite from coal fly ash using waste industrial brine solution, J. Environ. Sci. Health, Part A. 46 (2011) 1699-1707. 
[19] O.B. Kotova, I.N. Shabalin, D.A. Shushkov, L.S. Kocheva, Hydrothermal synthesis of zeolites from coal fly ash, Adv. Appl. Ceram. 115 (2016) 152-157.

[20] T.A. Vereshchagina, E.A. Kutikhina, L.A. Solovyov, S.N. Vereshchagin, E. V. Mazurova, Y.Y. Chernykh, A.G. Anshits, Synthesis and structure of analcime and analcime-zirconia composite derived from coal fly ash cenospheres, Microporous Mesoporous Mater. 258 (2018) 228-235, https://doi.org/10.1016/J. MICROMESO.2017.09.011.

[21] R. Moriyama, S. Takeda, M. Onozaki, Y. Katayama, K. Shiota, T. Fukuda, H. Sugihara, Y. Tani, Large-scale synthesis of artificial zeolite from coal fly ash with a small charge of alkaline solution, Fuel 84 (2005) 1455-1461, https://doi.org/ 10.1016/J.FUEL.2005.02.026.

[22] Z.T. Yao, X.S. Ji, P.K. Sarker, J.H. Tang, L.Q. Ge, M.S. Xia, Y.Q. Xi, A comprehensive review on the applications of coal fly ash, Earth Sci. Rev. 141 (2015) 105-121, https://doi.org/10.1016/J.EARSCIREV.2014.11.016.

[23] R.N.M. Missengue, P. Losch, G. Sedres, N.M. Musyoka, O.O. Fatoba, B. Louis, P. Pale, L.F. Petrik, Transformation of South African coal fly ash into ZSM-5 zeolite and its application as an MTO catalyst, Compt. Rendus Chem. 20 (2017) 78-86, https://doi.org/10.1016/J.CRCI.2016.04.012.

[24] J.G. Muniz, A. Ramirez, J.M. Robles, P. Melo, J.C. Bocardo, A.M. Martinez, Synthesis and characterization of high silica zeolites from coal fly ash (CFA): two cases of zeolite syntheses from the same waste material, Lat. Am. Appl. Res. 40 (2010) 323-328.

[25] L.F. Petrik, R. Missengue-Na-Moutoula, A.E. Ameh, T. Hlatywayo, Process for Production of High Silica Content Zeolite from Fly Ash, 2019.

[26] R.N.M. Missengue, P. Losch, N.M. Musyoka, B. Louis, P. Pale, L.F. Petrik, Conversion of South African coal fly ash into high-purity ZSM-5 zeolite without additional source of silica or alumina and its application as a methanol-to-olefins catalyst, Catalysts 8 (2018) 124.

[27] A.E. Ameh, C.P. Eze, E. Antunes, M.-L.U. Cornelius, N.M. Musyoka, L.F. Petrik, Stability of fly ash-based BEA-zeolite in hot liquid phase, Catal. Today (2019), https://doi.org/10.1016/J.CATTOD.2019.08.006.

[28] P. Guo, N. Yan, L. Wang, X. Zou, Database mining of zeolite structures, Cryst. Growth Des. 17 (2017) 6821-6835.

[29] R. Yuvakkumar, V. Elango, V. Rajendran, N. Kannan, High-purity nano silica powder from rice husk using a simple chemical method, J. Exp. Nanosci. 9 (2014) $272-281$.

[30] S. Mor, C.K. Manchanda, S.K. Kansal, K. Ravindra, Nanosilica extraction from processed agricultural residue using green technology, J. Clean. Prod. 143 (2017) 1284-1290, https://doi.org/10.1016/J.JCLEPRO.2016.11.142.

[31] F. Yan, J. Jiang, K. Li, N. Liu, X. Chen, Y. Gao, S. Tian, Green synthesis of nanosilica from coal fly ash and its stabilizing effect on $\mathrm{CaO}$ sorbents for $\mathrm{CO} 2$ capture, Environ. Sci. Technol. 51 (2017) 7606-7615.

[32] K.-M. Li, J.-G. Jiang, S.-C. Tian, X.-J. Chen, F. Yan, Influence of silica types on synthesis and performance of amine-silica hybrid materials used for $\mathrm{CO} 2$ capture, J. Phys. Chem. C 118 (2014) 2454-2462.

[33] F. Cao, Y. Wu, J. Gu, J. Wang, Hydrothermal synthesis of nanocrystalline zeolite Beta by acid-catalyzed hydrolysis of teraethylorthosilicate, Mater. Chem. Phys. 130 (2011) 727-732, https://doi.org/10.1016/J.MATCHEMPHYS.2011.07.053.

[34] C. Yin, D. Tian, M. Xu, Y. Wei, X. Bao, Y. Chen, F. Wang, One-step synthesis of hierarchical mesoporous zeolite Beta microspheres from assembly of nanocrystals, J. Colloid Interface Sci. 397 (2013) 108-113, https://doi.org/10.1016/J. JCIS.2013.02.006.

[35] J. Zhang, P. Cao, H. Yan, Z. Wu, T. Dou, Synthesis of hierarchical zeolite Beta with low organic template content via the steam-assisted conversion method, Chem. Eng. J. 291 (2016) 82-93, https://doi.org/10.1016/J.CEJ.2016.01.088.

[36] G. Xiong, X. Liu, R. Zhao, J. Liu, J. Yin, Q. Meng, Z. Guo, L. Liu, Synthesis and crystallization mechanism of nano-sized zeolite beta aggregates via aerosol- assisted method, Microporous Mesoporous Mater. 249 (2017) 97-104, https://doi. org/10.1016/J.MICROMESO.2017.04.051.

[37] K. Möller, B. Yilmaz, R.M. Jacubinas, U. Müller, T. Bein, One-step synthesis of hierarchical zeolite beta via network formation of uniform nanocrystals, J. Am. Chem. Soc. 133 (2011) 5284-5295.

[38] N.D. Hould, A. Foster, R.F. Lobo, Zeolite beta mechanisms of nucleation and growth, Microporous Mesoporous Mater. 142 (2011) 104-115, https://doi.org/ 10.1016/J.MICROMESO.2010.11.024.

[39] F. Pan, X. Lu, Q. Zhu, Z. Zhang, Y. Yan, T. Wang, S. Chen, A fast route for synthesizing nano-sized ZSM-5 aggregates, J. Mater. Chem. 2 (2014) 20667-20675.

[40] C.S. Cundy, P.A. Cox, The hydrothermal synthesis of zeolites: precursors, intermediates and reaction mechanism, Microporous Mesoporous Mater. 82 (2005) 1-78, https://doi.org/10.1016/J.MICROMESO.2005.02.016.

[41] C. Manrique, A. Guzmán, J. Pérez-Pariente, C. Márquez-Álvarez, A. Echavarría, Effect of synthesis conditions on zeolite Beta properties and its performance in vacuum gas oil hydrocracking activity, Microporous Mesoporous Mater. 234 (2016) 347-360, https://doi.org/10.1016/J.MICROMESO.2016.07.017.

[42] A.A. Gabrienko, I.G. Danilova, S.S. Arzumanov, A.V. Toktarev, D. Freude, A. G. Stepanov, Strong acidity of silanol groups of zeolite beta: evidence from the studies by IR spectroscopy of adsorbed CO and 1H MAS NMR, Microporous Mesoporous Mater. 131 (2010) 210-216, https://doi.org/10.1016/J. MICROMESO.2009.12.025.

[43] N.D. Hould, S. Kumar, M. Tsapatsis, V. Nikolakis, R.F. Lobo, Structure and colloidal stability of nanosized zeolite beta precursors, Langmuir 26 (2010) 1260-1270.

[44] T.F. Chaves, H.O. Pastore, P. Hammer, D. Cardoso, As-synthesized TEA-BEA zeolite: effect of $\mathrm{Si} / \mathrm{Al}$ ratio on the Knoevenagel condensation, Microporous Mesoporous Mater. 202 (2015) 198-207, https://doi.org/10.1016/J. MICROMESO.2014.09.058.

[45] S. Mintova, V. Valtchev, T. Onfroy, C. Marichal, H. Knözinger, T. Bein, Variation of the $\mathrm{Si} / \mathrm{Al}$ ratio in nanosized zeolite Beta crystals, Microporous Mesoporous Mater. 90 (2006) 237-245, https://doi.org/10.1016/J.MICROMESO.2005.11.026.

[46] A. Vjunov, J.L. Fulton, D.M. Camaioni, J.Z. Hu, S.D. Burton, I. Arslan, J.A. Lercher, Impact of aqueous medium on zeolite framework integrity, Chem. Mater. 27 (2015) 3533-3545.

[47] H. Zhang, B. Xie, X. Meng, U. Müller, B. Yilmaz, M. Feyen, S. Maurer, H. Gies, T. Tatsumi, X. Bao, W. Zhang, D. De Vos, F.-S. Xiao, Rational synthesis of Beta zeolite with improved quality by decreasing crystallization temperature in organotemplate-free route, Microporous Mesoporous Mater. 180 (2013) 123-129, https://doi.org/10.1016/J.MICROMESO.2013.06.031.

[48] J. Holzinger, P. Beato, L.F. Lundegaard, J. Skibsted, Distribution of aluminum over the tetrahedral sites in ZSM-5 zeolites and their evolution after steam treatment, J. Phys. Chem. C 122 (2018) 15595-15613.

[49] K. Zhang, Z. Liu, X. Yan, X. Hao, M. Wang, C. Li, H. Xi, In situ assembly of nanoparticles into hierarchical Beta zeolite with tailored simple organic molecule, Langmuir 33 (2017) 14396-14404.

[50] M. Thommes, K. Kaneko, A. V Neimark, J.P. Olivier, F. Rodriguez-Reinoso, J. Rouquerol, K.S.W. Sing, Physisorption of gases, with special reference to the evaluation of surface area and pore size distribution (IUPAC Technical Report), Pure Appl. Chem. 87 (2015) 1051-1069.

[51] J. Kim, J. Han, T.S. Kwon, Y.-K. Park, J.-K. Jeon, Oligomerization and isomerization of dicyclopentadiene over mesoporous materials produced from zeolite beta, Catal. Today 232 (2014) 69-74, https://doi.org/10.1016/J. CATTOD.2014.02.004.

[52] B. Li, G. Song, Y. Wu, F. Li, J. Xue, Z. Lv, Synthesis and characterization of mesoporous zeolite Beta templated by a novel organosiloxane, J. Porous Mater. 24 (2017) 1673-1678. 